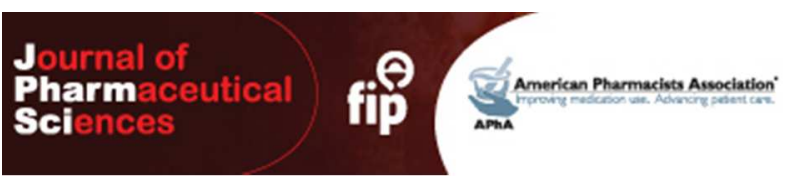

\title{
Stability hierarchy between piracetam forms I, II, and III from experimental pressure-temperature diagrams and topological inferences
}

\begin{tabular}{|r|l|}
\hline Journal: & Journal of Pharmaceutical Sciences \\
\hline Manuscript ID: & Draft \\
\hline Wiley - Manuscript type: & Research Article \\
\hline Date Submitted by the Author: & n/a \\
\hline Complete List of Authors: & $\begin{array}{l}\text { Toscani, Siro; Université de Rennes, Département de Chimie } \\
\text { Céolin, Rene; Université Paris Descartes, Faculté de Pharmacie } \\
\text { Barrio, Maria; Universitat Politècnica de Catalunya, Física i Enginyeria } \\
\text { Nuclear } \\
\text { Tamarit, Josep-Lluis; Universitat Politècnica de Catalunya, Física i } \\
\text { Enginyeria Nuclear } \\
\text { Louer, Daniel; Université de Rennes, Département de Chimie } \\
\text { Rietveld, Ivo; Université Paris Descartes, Faculté de Pharmacie }\end{array}$ \\
\hline Keywords: & $\begin{array}{l}\text { Calorimetry, Crystal polymorphism, X-ray powder diffractometry, Solid } \\
\text { state, Phase diagram, Phase transition, Physical characterization, Physical } \\
\text { stability, Preformulation, Thermodynamics }\end{array}$ \\
\hline & \\
\hline
\end{tabular}




\section{Stability Hierarchy between Piracetam}

Forms I, II, and III from Experimental Pressure-Temperature Diagrams and Topological Inferences

Siro Toscani1,2, René Céolin ${ }^{1}$, Léon Ter Minassian ${ }^{1, \dagger}$, Maria Barrio $^{3}$, Nestor Veglio ${ }^{3, \dagger}$, Josep-Lluis Tamarit ${ }^{3}$, Daniel Louër ${ }^{4}$, Ivo B. Rietveld ${ }^{1, *}$

${ }^{1}$ Laboratoire de Chimie Physique et Chimie Minérale, Faculté de Pharmacie, Université Paris Descartes, 4 avenue de l'observatoire, 75006 Paris, France

2Département de Chimie - UMR 6226, Faculté des Sciences, Université de Rennes 1, Bâtiment 10B, 263, Avenue du Général Leclerc, 35042 Rennes Cedex, France

${ }^{3}$ Grup de Caracterització de Materials (GCM), Departament de Física i Enginyeria Nuclear, Universitat Politècnica de Catalunya, Diagonal 647, 08028 Barcelona, Catalunya, Spain

${ }^{4}$ Formerly at Laboratoire de Chimie du Solide et Inorganique Moléculaire, CNRS and Université de Rennes I, France

tThese two authors have passed away, however they have contributed significantly in the early stages of this study

${ }^{*}$ corresponding author 


\begin{abstract}
The trimorphism of the active pharmaceutical ingredient piracetam is a famous case of polymorphism that has been frequently revisited by many researchers. The phase relationships between forms I, II, and III were ambiguous because they seemed to depend on the heating rate of the DSC and on the history of the samples or they have not been observed at all (equilibrium II-III). In the present paper, piezo-thermal analysis and high-pressure differential thermal analysis have been used to elucidate the positions of the different solid-solid and solid-liquid equilibria. The phase diagram, involving the three solid phases, the liquid phase and the vapor phase, has been constructed. It has been shown that form III is the high-pressure, low-temperature form and the stable form at room temperature. Form II is stable under intermediary conditions and form I is the low pressure, high temperature form, which possesses a stable melting point. The present paper demonstrates the strength of the topological approach based on the Clapeyron equation and the alternation rule when combined with high-pressure measurements.
\end{abstract}

Keywords: Calorimetry, Crystal polymorphism, X-ray powder diffractometry, Solid state, Phase diagram, Phase transition, Physical characterization, Physical stability, Preformulation, Thermodynamics 


\section{Introduction}

\subsection{The stability hierarchy of the three solid forms of piracetam}

The stability hierarchy of polymorphs is often based on transition temperature measurements by DSC and illustrated by schematic diagrams representing the Gibbs energy as a function of temperature.1,2 However, it may happen that this approach is incomplete and the trimorphism of piracetam is such an example for which the stability hierarchy remains unsolved. It is known for over a decade that forms II and III both transform endothermically into form I on heating; however, the onset temperatures of the two solid-solid transitions at equilibrium are not known, as they appear to depend on the investigator and on the sample used.

Kuhnert-Brandstätter et al. report an energy-temperature diagram in which the transition temperature of form II into form I ( $\left.T_{\mathrm{II} \rightarrow \mathrm{I}}\right)$ is about $348 \mathrm{~K}$ when measured by thermomicroscopy or about $377 \mathrm{~K}$ when measured by DSC. ${ }^{3}$ As the transition temperature of form III into form I ( $T_{\mathrm{III} \rightarrow \mathrm{I}}$ ) is about $388 \mathrm{~K}$ when measured by DSC, which is higher than $T_{\mathrm{II} \rightarrow \mathrm{I}}$, the authors conclude that form III is the more stable phase at room temperature. ${ }^{3}$ They also mention that "the relative high stability of mod. II can be explained by the small difference of energetic data between mod. II and mod. III."

Picciochi et al. concluded that "the results of solution and DSC experiments indicate that the stability hierarchy of forms I, II, and III at $298.15 \mathrm{~K} \ldots$ is III $>$ II > I".4

Maher et al. reported a $\Delta G$ - T diagram exhibiting endothermic transitions II $\rightarrow$ I and $\mathrm{III} \rightarrow \mathrm{I}$ below $363 \mathrm{~K}$ and below $368 \mathrm{~K}$ respectively, thus leading to the conclusion that form III is the more stable form below $368 \mathrm{~K}^{5}$

Céolin et al. reported that the endothermic transitions $\mathrm{III} \rightarrow \mathrm{I}$ and $\mathrm{II} \rightarrow \mathrm{I}$ occur at $392 \mathrm{~K}$ and $399 \mathrm{~K}$ respectively, thus inferring that form II is the more stable phase below $392 \mathrm{~K}^{6}$

Although a tendency can be observed that form III is the more stable phase at room temperature, the large variation of solid-solid transition temperatures in the different papers warrants an alternative approach to determine the stability hierarchy of the polymorphs without ambiguity. In this paper, it will be demonstrated how the stability hierarchy can be inferred from experimental pressure-temperature diagrams. 


\subsection{Literature data}

\subsubsection{Crystallographic data}

Three solid forms of piracetam $\left(\mathrm{C}_{6} \mathrm{H}_{10} \mathrm{~N}_{2} \mathrm{O}_{2}, M=142.16 \mathrm{~g} \mathrm{~mol}^{-1}\right)$ have been structurally characterized under ambient conditions (Table 1 and Table S1 in the Supporting Information), and two more forms as well as two hydrates have been obtained under pressure: form IV (monoclinic, P2 $1 /$ c), ${ }^{7}$ form V (triclinic, P-1), ${ }^{8}$ a monohydrate, ${ }^{7}$ and a dihydrate $^{8}$. From the data in Table 1, it can be inferred that form III is the denser form, while form I is the less dense one.

Table 1. Specific volumes ( $v$ ) from the literature of the three solid forms of piracetam obtained under ambient conditions

\begin{tabular}{|l|l|l|l|l|}
\hline Form & System, space group & $\begin{array}{l}v \\
/ \mathrm{cm}^{3} \mathrm{~g}^{-1}\end{array}$ & $\begin{array}{l}T \\
/ \mathrm{K}\end{array}$ & Ref. \\
\hline I & Monoclinic P2 $1 / \mathrm{n}$ & 0.7661 & R.T. & 9 \\
& & 0.7518 & 150 & 7 \\
\hline II & Triclinic P-1 & 0.7383 & R.T. & 10 \\
& & 0.7094 & 100 & 11 \\
\hline III & Monoclinic P2 $1 / \mathrm{n}$ & 0.7216 & R.T. & 12 \\
& & 0.7321 & R.T. & 10 \\
& & 0.7245 & R.T. & 13 \\
& & 0.7251 & 290 & 14 \\
& & 0.7058 & 100 & 11 \\
\hline
\end{tabular}

\subsubsection{Calorimetric data}

The thermal behavior of piracetam polymorphs has been described by several authors (see Table 2). From the data in Table 2, it can be inferred that $\Delta_{\mathrm{II} \rightarrow \mathrm{I}} h$ is consistently

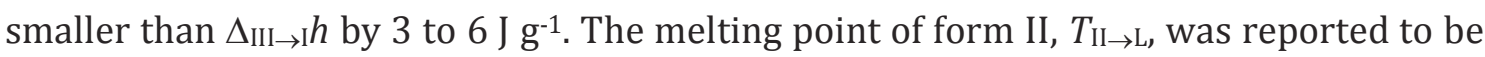
$415.5 \mathrm{~K}^{3}$ or $415 \mathrm{~K}^{6}$, but this information should be considered cautiously because it is based on the optical observation of a change in morphology ${ }^{3}$ or the presence of a very small endothermic peak in a few DSC curves ${ }^{6}$. 
Table 2. Calorimetric data for piracetam forms I, II, and III from the literature

\begin{tabular}{|c|c|c|c|c|c|c|c|c|}
\hline $\begin{array}{l}T_{\text {II-I }} \\
/ \mathrm{K}\end{array}$ & $\begin{array}{l}\Delta_{\mathrm{II} \rightarrow \mathrm{I}} h \\
/ \mathrm{J} \mathrm{g}^{-1}\end{array}$ & $\begin{array}{l}T_{\text {III-I }} \\
/ \mathrm{K}\end{array}$ & $\begin{array}{l}\Delta_{\mathrm{III} \rightarrow \mathrm{I}} h \\
/ \mathrm{J} \mathrm{g}^{-1}\end{array}$ & $\begin{array}{l}T_{\text {I-liq }} \\
/ \mathrm{K}\end{array}$ & $\begin{array}{l}\Delta_{\mathrm{I} \rightarrow \mathrm{liq}} h \\
/ \mathrm{J} \mathrm{g}^{-1}\end{array}$ & $\begin{array}{l}T_{\text {III-liq }} \\
/ \mathrm{K}\end{array}$ & $\begin{array}{l}\Delta_{\mathrm{III} \rightarrow \mathrm{liq}} h \\
/ \mathrm{J} \mathrm{g}^{-1}\end{array}$ & Ref. \\
\hline 382 & 23.71 & 393 & 26.45 & - & - & - & - & 15 \\
\hline 382 & 23.92 & 392 & 26.73 & 423 & 179.38 & - & - & 5 \\
\hline 348 or 377 & 21 & 390 & 26.7 & 426 & 180.7 & 413 & 206 & 3 \\
\hline 399 & 24 & 392 & 28 & 426 & 180 & 412 & 210 & 6 \\
\hline 382.7 & 22.72 & 394.4 & 26.24 & 425.9 & $\begin{array}{l}176.6 \text { or } \\
182.9\end{array}$ & & & 4 \\
\hline
\end{tabular}

\section{Material and Methods}

\subsection{Samples}

Piracetam forms II and III of medicinal grade were obtained from Isochem, France. They were used as such after verification by differential scanning calorimetry and highresolution X-ray powder diffraction. Form I, which is not persistent at RT, was obtained from either of these polymorphs by heating above the transition temperature and quenching. 6

\subsection{Differential scanning calorimetry}

Three DSC analyzers were used to determine the temperatures and heats of transition: a TA Instruments (USA) DSC10 Differential Scanning Calorimeter, a Q100 thermal analyzer from TA-Instruments (USA), and a Mettler-Toledo (Switzerland) 822e thermal analyzer. Indium $\left(T_{\text {fus }}=429.75 \mathrm{~K}, \Delta_{\text {fus }} H=3.267 \mathrm{~kJ} \cdot \mathrm{mol}^{-1}\right)$ and zinc $\left(T_{\text {fus }}=692.68 \mathrm{~K}, \Delta_{\text {fus }} H\right.$ $=7.320 \mathrm{~kJ} \cdot \mathrm{mol}^{-1}$ ) were used as standards for temperature and enthalpy calibration. Specimens were weighed with microbalances sensitive to $0.01 \mathrm{mg}$ and sealed in aluminum pans.

\subsection{High resolution $X$-ray powder diffraction}

Two series of non-ambient X-ray powder diffraction data were obtained for the thermal expansion study.

A Bragg-Brentano optics was used with a Bruker D5005 powder diffractometer, equipped with an Anton Paar high-temperature oven camera HTK1200. Cu $K \alpha_{1,2}$ X-rays were obtained with a diffracted-beam graphite monochromator. Powders were pressed on a Ni grid sample-holder in order to reduce transparency effects. Samples of forms II 
and III were heated above $400 \mathrm{~K}$ and upon cooling form I was observed. It must be noted that volume changes during phase transformations may affect the quality of the sample surface (the volumes per formula units are $4.6 \%$ and $3.8 \%$ greater for form I than for forms III and II, respectively). The powder data were collected at selected temperatures under air. Previous diffraction studies showed a short life time of samples of form I obtained from samples of forms II and III quenched at room temperature. ${ }^{6}$ To reduce the time required for data collection, the diffraction patterns were scanned over the angular range $10-35^{\circ}(2 \theta)$, with a step size of $0.025^{\circ}(2 \theta)$ and 3 s step-1. Due to the low counting statistics, the accuracy of the results is moderate. The peak positions were evaluated with the software WinPLOTR. ${ }^{16}$ For each pattern the better defined diffraction lines were selected and twenty peak positions were input in the indexing program DICVOL14. ${ }^{17}$ The cell parameters are least-squares refined, as well as the zero-point position of the patterns.

A Debye-Scherrer optics was used with an INEL powder diffractometer equipped with a cylindrical position-sensitive detector (CPS120) containing 4096 channels $\left(0.029^{\circ} 2 \theta\right.$ angular step) and monochromatic $\mathrm{Cu} \mathrm{K \alpha} 1(\lambda=1.54061 \AA)$ radiation. For the measurements as a function of temperature, a liquid nitrogen 700 series Cryostream Cooler from Oxford Cryosystems (UK) was used. Slightly ground specimens were introduced in a Lindemann capillary $(0.5 \mathrm{~mm}$ diameter) rotating perpendicularly to the $\mathrm{X}$-ray beam during the experiments to improve the average over the crystallite orientations. For the temperature-dependent measurements in the range from $100 \mathrm{~K}$ up to the melting point, the sample temperature was equilibrated for about $10 \mathrm{~min}$ followed by an acquisition time of ca. 1 hour. The heating rate in between data collection was 1.33 $\mathrm{K} \mathrm{min}^{-1}$. The powder data were analyzed with the software FULLPROF using pattern matching. 18

\subsection{Specific volume of molten piracetam}

$10.1223 \mathrm{~g}$ of piracetam (weighed with a microbalance sensitive to $0.1 \mathrm{mg}$ ) was introduced in a cylindrical silica tube with a flat bottom, whose mean inner diameter $(8.152 \mathrm{~mm})$ was obtained with a DIGI-MET ${ }^{\circledR}$ 3-point alesometer with a precision of $0.003 \mathrm{~mm}$ (see below Table S7, Supporting Information). After being sealed under vacuum, the tube was suspended in a XU 75/300 oven from Climats (France) whose inner temperature, controlled at $\pm 1 \mathrm{~K}$, was allowed to vary slowly between successive measurements in the 390 - $470 \mathrm{~K}$ range. The height of the melt was measured through 
the window of the door of the oven with a cathetometer sensitive to $2 \mu \mathrm{m}$.

\subsection{Sublimation-condensation experiment}

A specimen of form III was placed at one end of a cylindrical silica tube (29 cm length), which was sealed under vacuum. It was introduced in a horizontal furnace so that the specimen-containing end was maintained at about $414 \mathrm{~K}$ and the other end was outside the furnace at room temperature. Crystals grew by condensation of the vapor phase within 6 days (Figure 1).

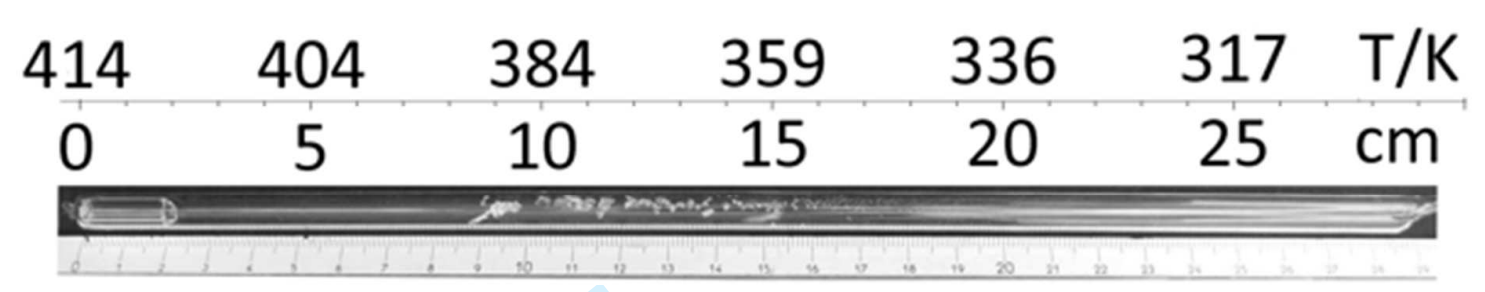

Figure 1. Sublimation-condensation of piracetam crystals in a silica tube subjected to a temperature gradient for 6 days. The initial sample (form III) was placed in the small container on the left-hand side and maintained at $414 \mathrm{~K}$.

\subsection{Piezo-thermal analysis (PTA)}

An in-house constructed piezo-thermal analyzer, whose operating principle and design have been described elsewhere,19-22 was used to record the thermal effects associated with phase transitions investigated isothermally as a function of pressure. Pressure was gradually decreased under isothermal conditions at a rate of 20 or $50 \mathrm{MPa} \mathrm{h}^{-1}$ from a maximum pressure of $600 \mathrm{MPa}$ down to atmospheric pressure. The measurement range for the temperature of the equipment is 298 to $490 \mathrm{~K}$. The weight of the specimens (about $15 \mathrm{mg}$ ) was determined with a microbalance sensitive to $0.01 \mathrm{mg}$. It is important to point out that PTA allows precise entropy change measurements as a function of pressure because the fluxmeter of the device records enthalpy changes at constant temperature.

\subsection{High-pressure differential thermal analysis.}

The transitions in piracetam have been studied with high-pressure differential thermal analysis (HP-DTA). An in-house constructed HP-DTA, similar to the apparatus previously built by Würflinger ${ }^{23}$ with temperature and pressure ranges from 203 to 473 $\mathrm{K}$ and 0 to $300 \mathrm{MPa}$, respectively, was used. Unweighed samples (about 10 to $50 \mathrm{mg}$ ) were sealed in cylindrical tin pans and to ensure that in-pan volumes were free from 
residual air, specimens were mixed with an inert perfluorinated liquid (Galden ${ }^{\circledR}$ from Bioblock Scientifics, Illkirch, France) before sealing. HP-DTA scans were carried out with a heating rate of $2 \mathrm{~K} \mathrm{~min}^{-1}$. In addition, DSC experiments at ordinary pressure (i.e., in standard aluminum pans) with mixtures of piracetam and perfluorinated liquid were carried out to verify that the liquid was inert.

\section{Results}

\subsection{Calorimetric data}

Two series of experiments were carried out to investigate whether the transition temperatures $\mathrm{II} \rightarrow \mathrm{I}$ and $\mathrm{III} \rightarrow \mathrm{I}$ depend on the history of the samples (see details in the Supporting Information Tables S2 and S3). It can be seen in Figure 2a that the temperature intervals in which the two solid-solid transitions occur fully overlap at the heating rates of 5 and $10 \mathrm{~K} \mathrm{~min}^{-1}$.

Hence, aliquots of forms II and III were ground to obtain fine powders with about the same grain size (verified by optical microscopy). Each has been heated at various rates to investigate their dependence on the heating rate and to compare the two samples. From the data, shown in Figure 2b (see also the Supporting Information Table S2-S5), the following has been concluded: (1) the melting temperature of form I is virtually independent of the heating rate, (2) transitions $\mathrm{III} \rightarrow \mathrm{I}$ and $\mathrm{II} \rightarrow \mathrm{I}$ are heating-rate dependent, and (3) it is inconclusive which of the two forms transforms at the lowest temperature into form I. It is not uncommon to observe solid-solid transitions that are heating rate dependent; $24-26$ however a complete overlap in temperature range of two distinct transitions is rare.

A statistical analysis of the transition temperatures for the two solid-solid transitions obtained with heating rates of 5 and $10 \mathrm{~K} \mathrm{~min}^{-1}$ (see Supporting Information Tables S2 to S5) is entirely inconclusive as to which of the two forms, II or III, transforms into form I first: $\mathrm{T}_{\mathrm{II} \rightarrow \mathrm{I}} 390.62 \mathrm{~K}$ and $\mathrm{T}_{\mathrm{III} \rightarrow \mathrm{I}} 389.04 \mathrm{~K}\left(\mathrm{~T}_{\mathrm{II} \rightarrow \mathrm{I}}: 12\right.$ values, $\min 372.35 \mathrm{~K}, \max 402.82 \mathrm{~K}, \sigma$ $=9.4 \mathrm{~K}$ and $\mathrm{T}_{\mathrm{III} \rightarrow \mathrm{I}}: 18$ values $\min 363.33 \mathrm{~K}, \max 406.86 \mathrm{~K}, \sigma=12.5 \mathrm{~K}$ ). Average values of the transition quantities (compiled in the Tables S2 to S5 in the Supporting Information) have been reported in Table 3. 

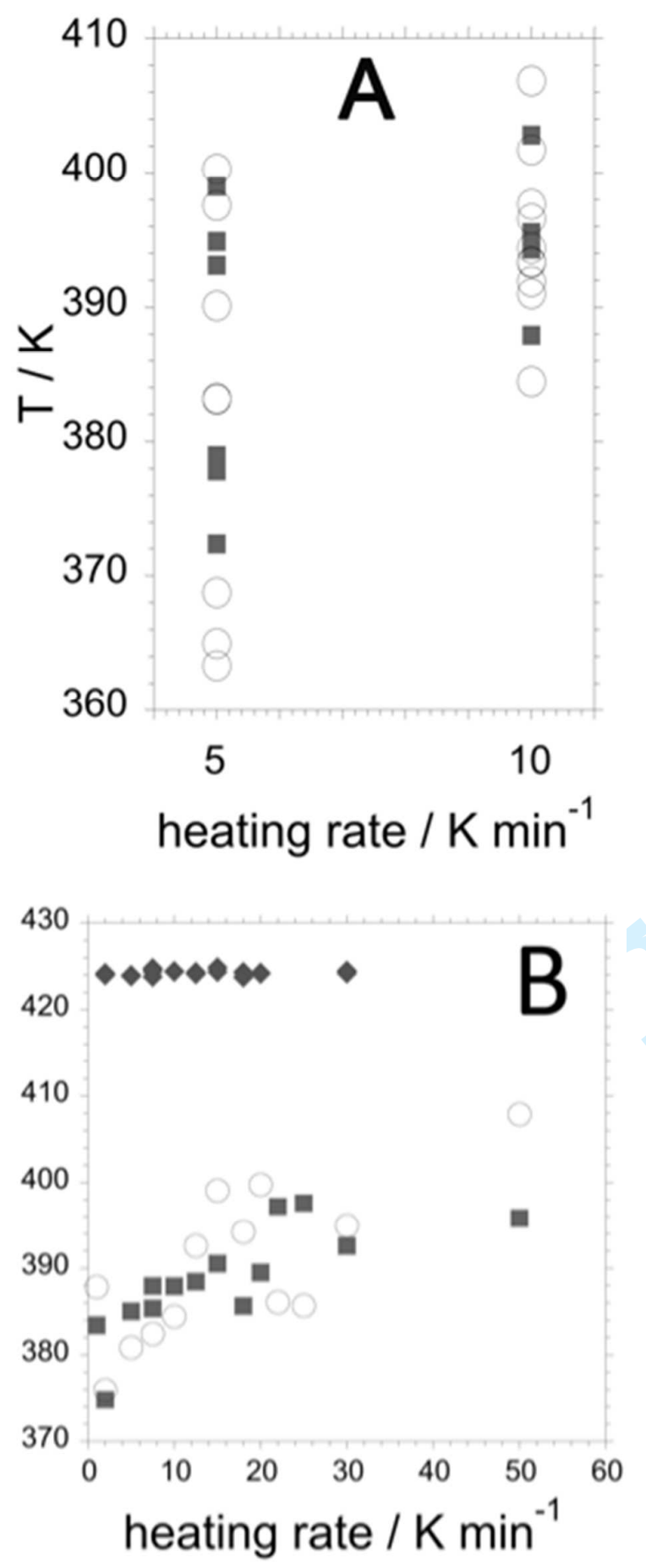

Figure 2. Onset temperatures of transitions II $\rightarrow$ I (solid squares), III $\rightarrow$ I (open circles) and melting of form I (solid diamonds) (A) of samples obtained by different methods and heated at 5 or $10 \mathrm{~K} \mathrm{~min}^{-1}$ (see for details Table S2 to S5) and (B) as a function of the heating rate.

Some unground specimens of form III crystals obtained from methanol did not 
transform to form I but melted. Tentatively, this could be explained by the presence of methanol in the crystal at a level of about $1 \%$ of the initial mass, as determined by thermogravimetric analysis. Thus, methanol as an impurity may be able to stabilize form III up to its melting point. However, this also means that the specific melting enthalpy of form III obtained from these measurements needs to be corrected for the solvent weighed in before the measurement run. Thus, the apparent melting enthalpy for form III from the measurements is $1 \%$ smaller than the actual value for pure form III. The melting enthalpy has been corrected for this error as reported in Table 3. It is clear that the experimental $\Delta_{\mathrm{III} \rightarrow \text { liq }} h$ virtually matches the value $214.62 \mathrm{~J} \mathrm{~g}^{-1}$ calculated by adding $\Delta_{\mathrm{III} \rightarrow \mathrm{I}} h$ to $\Delta_{\mathrm{I} \rightarrow \mathrm{liq}} h$.

Table 3. Summary of the calorimetric data obtained for forms I, II, and III of piracetam from 5 series of DSC experiments (see Tables S2 to S5 in the Supporting Information)

\begin{tabular}{|c|c|c|c|c|c|}
\hline & $\begin{array}{l}\text { Number } \\
\text { of values }\end{array}$ & $\begin{array}{l}\text { Lowest } \\
\text { value }\end{array}$ & $\begin{array}{l}\text { Highest } \\
\text { value }\end{array}$ & Mean & $\begin{array}{l}\text { Standard } \\
\text { deviation }\end{array}$ \\
\hline$T_{\text {II-I }} / \mathrm{K}^{\mathrm{a}}$ & 12 & 372.9 & 402.8 & 390.6 & 9.4 \\
\hline$T_{\text {III-I }} / \mathrm{K}^{\mathrm{a}}$ & 18 & 363.3 & 406.9 & 389.0 & 12.5 \\
\hline$\Delta_{\mathrm{II} \rightarrow I} h / \mathrm{J} \mathrm{g}^{-1}$ & 23 & 22.9 & 25.9 & 24.4 & 0.9 \\
\hline$\Delta_{\mathrm{III} \rightarrow \mathrm{I}} h / \mathrm{J} \mathrm{g}^{-1}$ & 26 & 25.2 & 30.1 & 27.5 & 1.2 \\
\hline$\Delta_{\mathrm{I} \rightarrow \mathrm{liq}} h / \mathrm{J} \mathrm{g}^{-1}$ & 49 & 174.9 & 195.4 & 187.1 & 4.3 \\
\hline$T_{\text {I-liq }} / \mathrm{K}$ & 49 & 423.3 & 425.6 & 424.5 & 0.5 \\
\hline$\Delta_{\text {III } \rightarrow \mathrm{liq}} h / \mathrm{J} \mathrm{g}^{-1}$ & 7 & $\begin{array}{l}(205.0) \\
207.1^{b}\end{array}$ & $\begin{array}{l}(217.1) \\
219.3^{b}\end{array}$ & $\begin{array}{l}(211.5) \\
213.6^{a}\end{array}$ & 4.4 \\
\hline$T_{\text {III-liq }} / \mathrm{K}$ & 7 & 411.9 & 412.8 & 412.3 & 0.34 \\
\hline
\end{tabular}

aAverage for 5 and $10 \mathrm{~K} \mathrm{~min}^{-1}$ only

bValues adjusted for the presence of 1 mass $\%$ of methanol in form III, the measured apparent melting enthalpies are provided in parentheses.

\subsection{Sublimation-condensation experiment}

As can be seen in Figure 1, big crystals deposited in the temperature range from 390 down to $360 \mathrm{~K}$, while small crystals had formed in the colder part of the tube below 360 K. X-ray diffraction of ground big crystals (390-360 K range) led to the diffraction 
pattern of form II. The small crystallites formed below $360 \mathrm{~K}$ exhibited a mixed diffraction pattern of forms II and III. Taking the calorimetric measurements into account, it would be expected that above $360 \mathrm{~K}$ form I deposits. After the tube is extracted from the furnace and cooled to room temperature, form I will have transformed relatively rapidly to form II. This has also been observed previously by Xray diffraction. ${ }^{6}$ The simultaneous observation of form II and form III crystals just above and at ambient temperature demonstrates that any stability difference between them is probably rather small.

\subsection{Specific volume and thermal expansion of forms I, II, and III}

Two series of experiments as a function of temperature have been carried out. The data are compiled in the Supporting Information Tables S6a and S6b. Using all available data for the specific volumes ( $v_{\mathrm{I}}, v_{\mathrm{II}}$, and $v_{\mathrm{III}}$ in $\left.\mathrm{cm}^{3} \mathrm{~g}^{-1}\right)$ as a function of temperature $(\mathrm{K})$, the following three equations were obtained:

$$
\begin{array}{ll}
V_{\mathrm{I}}=0.7219+0.00016026 T & r^{2}=0.960 \\
V_{\mathrm{II}}=0.69661+0.00013037 T & r^{2}=0.992 \\
V_{\text {III }}=0.69341+0.00011618 T & r^{2}=0.993
\end{array}
$$

Expressed in expansivities, the expressions lead to $\alpha_{v, \mathrm{I}}=2.22 \times 10^{-4} \mathrm{~K}^{-1}, \alpha_{v, \mathrm{II}}=1.87 \times 10^{-4}$ $\mathrm{K}^{-1}$, and $\alpha_{v, \text { III }}=1.68 \times 10^{-4} \mathrm{~K}^{-1}$. These expansivities are all near the value of $2 \times 10^{-4} \mathrm{~K}^{-1}$ reported by Gavezzotti for organic molecular compounds ${ }^{27}$ and for organic molecular APIs a similar trend has been observed. ${ }^{28,29}$ In addition, it can be seen in Figure 3 that the eqs. 1-3 are in close agreement with volumes obtained from single crystals at 100 and $150 \mathrm{~K}$ for all three forms. 


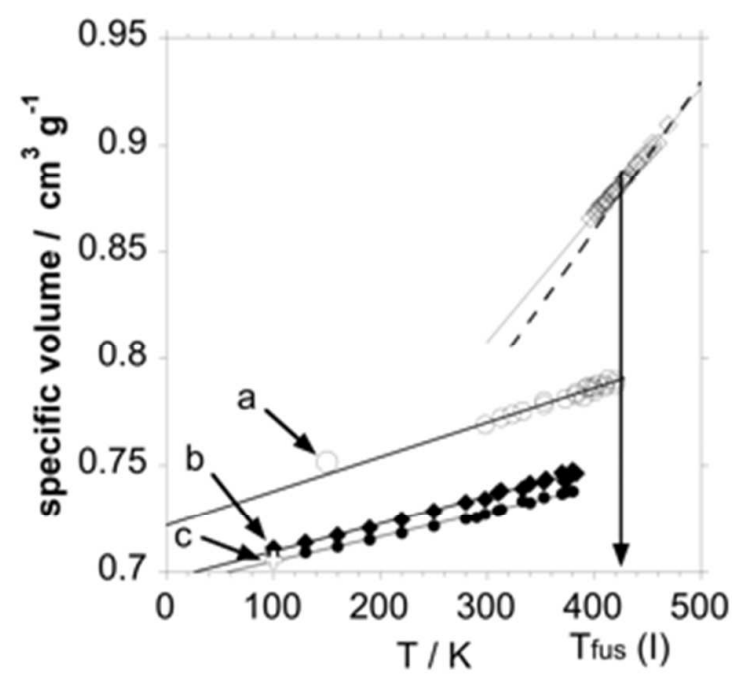

Figure 3. Specific volumes of piracetam forms I (open circles, eq. 1), II (solid diamonds, eq. 2) and III (solid circles, eq. 3) as a function of temperature from high-resolution Xray powder diffraction and comparison with volumes from single crystal structures (a: ref $8, \mathrm{~b}$ and c: ref ${ }^{11}$ ). The experimental (eq. $4 \mathrm{a}$, open diamonds) and calculated (eq. $4 \mathrm{~b}$, dashed line, see text) specific volumes of liquid piracetam are also provided.

\subsection{Specific volume of molten piracetam as a function of temperature}

The specific volume obtained by measurement of liquid piracetam as a function of temperature is presented in Figure 3 (compiled in the Supporting Information in Table S7). The data is fit to the expression (units as in eqs. 1-3):

$V_{\text {liq }}=0.6291+0.0005952 T \quad r^{2}=0.994$

Molecular organic compounds (including pharmaceuticals) often degrade in the molten state and therefore eq. 4a should be considered as approximate. However, this expression can be compared to the liquid expansion obtained via a different approach. The thermal expansion of the liquid can be estimated assuming that: (1) the specific volume of the melt at the temperature of fusion is in the order of 1.11 times the specific volume of its solid and (2) the mean expansivity $\alpha_{\mathrm{v} \text {,liq }}$ of the melt is $1.2 \times 10^{-3} \mathrm{~K}^{-1.28-31}$ With these two approximations, one obtains the dependence of the specific volume of the melt on the temperature (units as eqs. 1-4a):

$v_{\text {liq }}=0.5810+0.0006971 T$ 
This equation leads to values close to the experimental ones in the temperature range from 420 to $500 \mathrm{~K}$ (Figure 3).

\subsection{Piezo-thermal analysis}

The melting pressures $(P / \mathrm{MPa})$ of forms I and III have been measured isothermically in decreasing pressure runs for a set temperature in the temperature range of 412 to $443 \mathrm{~K}$ together with the transition enthalpy, leading also to the entropy and specific volume changes (see the Supporting Information Table S8 for numerical data). The P,T melting curves were fitted to straight lines:

$$
\begin{array}{ll}
P_{\mathrm{I}-\mathrm{liq}}=-2529+5.956 T & r^{2}=0.998 \\
P_{\mathrm{III}-\mathrm{liq}}=-1878+4.555 T & r^{2}=0.997
\end{array}
$$

When decreasing the pressure in the apparatus from a pressure higher than $200 \mathrm{MPa}$, the transition III $\rightarrow$ I was always observed, also for samples that were initially loaded as form II. This indicates that form II transforms into form III under a sufficiently high pressure i.e. >200 MPa. Measurement runs of form II starting below $200 \mathrm{MPa}$, in contrast, gave rise to the II $\rightarrow$ I transition on decreasing the pressure.

Transitions III $\rightarrow$ I and II $\rightarrow$ I could be easily identified by their respective enthalpies (see Table 3). The resulting $P(\mathrm{MPa}), T(\mathrm{~K})$ data are reported in the Supporting Information Table S9. They were fitted to the following straight lines:

$P_{\text {III-I }}=-681.2+1.886 T \quad r^{2}=0.987$

$P_{\text {II-I }}=-899.5+2.409 T \quad r^{2}=0.992$

The enthalpy changes obtained at high pressure (see the Supporting Information Tables S8 and S9) are similar to the values obtained in a standard DSC apparatus and virtually no change is observed (within the experimental limits).

\subsection{High-Pressure Thermal Analysis}

The temperatures $(T / K)$ of fusion of forms I and III measured at different pressures $(P / \mathrm{MPa})$ are compiled in the Supporting Information Table S10. Linear fits to the data 
lead to the following equations:

$$
\begin{array}{ll}
P_{\mathrm{I}-\mathrm{liq}}=-3714+8.728 T & r^{2}=0.968 \\
P_{\mathrm{III}-\mathrm{liq}}=-1978+4.814 T & r^{2}=0.993 \\
P_{\mathrm{III}-\mathrm{I}}=-785.7+2.118 T & r^{2}=0.964 \\
P_{\mathrm{II}-\mathrm{I}}=-1531+3.933 T & r^{2}=0.958
\end{array}
$$

\section{Discussion}

\subsection{Preliminary phase diagram using only experimental data points}

The aim of the discussion is to construct a complete pressure-temperature phase diagram of the trimorphism of piracetam in combination with the stability hierarchy of the different equilibria and phases. In first instance, the experimental $P$ - $T$ data will be taken into consideration and this will subsequently be completed through thermodynamic arguments and other data.

For certain high-pressure measurements, different slopes can be observed for the same transition depending on the method used (cf. eqs. 8a and b). Nevertheless, irrespective of the method, the inequalities between the $\mathrm{d} P / \mathrm{d} T$ slopes of the two-phase equilibria is consistently $\mathrm{d} P / \mathrm{d} T_{\text {I-liq }}>\mathrm{d} P / \mathrm{d} T_{\text {III-liq }}>\mathrm{d} P / \mathrm{d} T_{\text {I-II }}>\mathrm{d} P / \mathrm{d} T_{\text {I-III. }}$ This is illustrated in Figure 4 with expressions using the combined data from both high-pressure methods:

$$
\begin{array}{ll}
P_{\mathrm{I}-\mathrm{liq}}=-3109+7.317 T & r^{2}=0.914 \\
P_{\mathrm{III}-\mathrm{liq}}=-2022+4.904 T & r^{2}=0.990 \\
P_{\mathrm{III-I}}=-676.8+1.871 T & r^{2}=0.977 \\
P_{\text {II-I,PTA }}=-899.5+2.409 T & r^{2}=0.992 \\
P_{\text {II-I,HP-DTA }}=-1531+3.933 T & r^{2}=0.958
\end{array}
$$




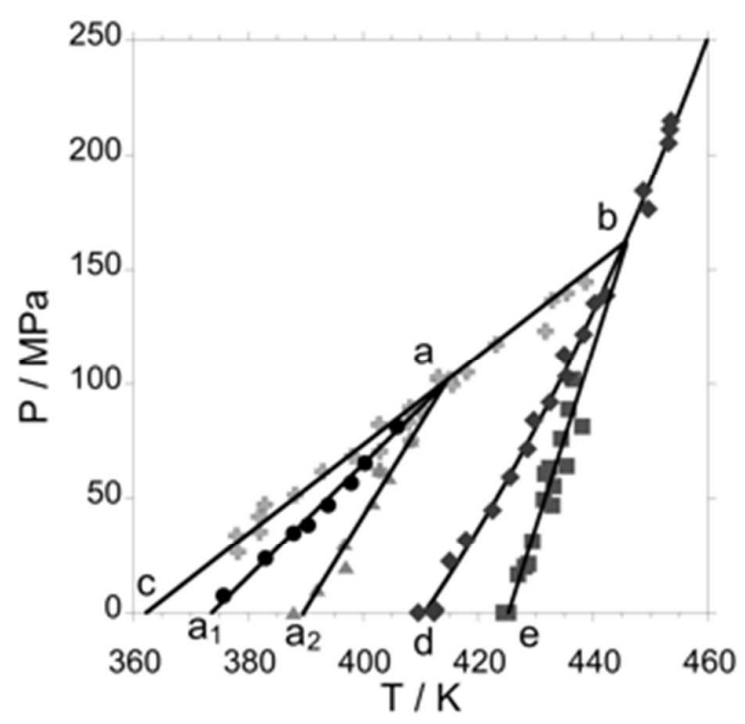

Figure 4. Pressure-temperature phase diagram of the phase transitions of piracetam with experimental data points only. Fusion of form I: squares, fusion of form III: diamonds, III $\rightarrow$ I: plus sign, II $\rightarrow \mathrm{I}_{\text {PTA: }}$ circles, and II $\rightarrow \mathrm{I}_{\text {HP-DTA: }}$ triangles.

The high-pressure results from the two different methods could be smoothly combined into single expressions with the exception of transition II $\rightarrow$ I whose HP-DTA curve is steeper and clearly separated from the curve obtained by PTA. Nevertheless, it can be observed that both lines converge at the exact same point (point ' $a$ ' in Figure 4), where the I-III equilibrium line intersects. It is therefore likely that point 'a' is the I-II-III triple point. Because piezothermal analysis is an isothermal method, the temperatures at which transitions are observed are not heating-rate dependent, therefore, it could be suggested that the line ' $a-a_{1}$ ' in Figure 4 coincides more accurately with the I-II equilibrium line.

It should also be noted that, although the whole line 'b-c' has been identified as the equilibrium I-III through its enthalpy value, once this line intersects the triple point I-IIIII (point 'a') it must change its stability ranking. If no hydrostatic pressure is applied (i.e. in a standard DSC) transitions III $\rightarrow$ I and II $\rightarrow \mathrm{I}$ should ideally be observed at $361.7 \mathrm{~K}$ (eq. (7c)) and 373.4 K (eq. (8a)), respectively. Since curve 'a-a2' in Figure 4 converges with curves ' $a-a 1$ ' and 'b-c' at point ' $a$ ', it may be tentatively inferred that the influence of the heating rate on the temperature of transition II $\rightarrow$ I decreases with increasing pressure. 
It is also clear that the I-III-liq triple point (where the equilibria I-III, I-liq, and III-liq intersect, point ' $b$ ' in Figure 4) will be located at a lower temperature than that of triple point I-II-liq (Not shown in Figure 4) because equilibrium I-III crosses equilibrium I-liq at a lower temperature than equilibrium I-II does.

\subsection{Triple point I-II-III and equilibrium curve II-III}

Triple point I-II-III is the intersection of the I-II and I-III equilibrium curves (point ' $a$ ' in Figure 4). Thus, by setting eqs. (7c) and (8a), or (7c) and (8b) equal, the coordinates of triple point I-II-III are found to be $T_{\text {I-II-III }} \cong 414 \mathrm{~K}$ and $P_{\text {I-II-III }} \cong 95.5 \mathrm{MPa}$.

Equilibrium II-III must pass through triple point I-II-III too, even though it has not been observed experimentally. To determine the value of its $\mathrm{d} P / \mathrm{d} T$ slope, one can make use of the fact that the equalities $\Delta_{\mathrm{III} \rightarrow \mathrm{II} S}=\Delta_{\mathrm{III} \rightarrow I} S-\Delta_{\mathrm{II} \rightarrow I} S$ and $\Delta_{\mathrm{III} \rightarrow \mathrm{II}} V=\Delta_{\mathrm{III} \rightarrow \mathrm{I}} V-\Delta_{\mathrm{II} \rightarrow \mathrm{I}} V$ hold at the triple point I-II-III. Using mean $\Delta s$ and $\Delta v$ values calculated with the values compiled in Table S9 in the Supporting Information, one finds $\Delta_{\mathrm{III} \rightarrow \mathrm{II} S}=0.078-0.068=0.010 \mathrm{~J} \mathrm{~K}^{-1} \mathrm{~g}^{-1}$, and $\Delta_{\mathrm{III} \rightarrow \mathrm{IIV}}=0.0385-0.0282=0.0103 \mathrm{~cm}^{3} \mathrm{~g}^{-1}$, which results in a $\mathrm{d} P / \mathrm{d} T_{\mathrm{II}-\mathrm{III}}$ of $0.97 \mathrm{MPa} \mathrm{K}-$ 1 through the Clapeyron equation:

$\mathrm{d} P / \mathrm{d} T=\Delta s / \Delta v=\Delta h /(T \Delta v)$

Using the triple point as a coordinate on the II-III equilibrium line one finds for its $P$ (/PMa) - $T$ (/K) relationship:

$P_{\mathrm{II}-\mathrm{III}}=-306+0.97 T$

At $P_{\mathrm{II}-\mathrm{III}}=0 \mathrm{MPa}$, eq. 10 becomes $316 \mathrm{~K}$. This is the temperature for triple point II-III-vap, as the vapor pressure of molecular substances around room temperature generally ranges between a few pascal up to a few hundred pascal and $P$ in megapascal is approximately zero.

The slope of eq. 10 has been calculated using the entropy obtained by PTA. If instead one uses the mean enthalpy changes obtained in a standard DSC (Table 3), as would be the case for the topological approach, the entropy difference between forms II and III will be $0.0077 \mathrm{~J} \mathrm{~K}^{-1} \mathrm{~g}^{-1}$ at the triple point temperature of $414 \mathrm{~K}$. Using the volume change obtained by X-ray diffraction $v_{\mathrm{II}}-V_{\mathrm{III}}=0.00907 \mathrm{~cm}^{3} \mathrm{~g}^{-1}$ at $414 \mathrm{~K}$ (eqs. 2 and 3), the slope $\mathrm{dP} / \mathrm{dT}_{\text {II-III }}$ calculated with eq. 9 is $0.85 \mathrm{MPa} \mathrm{K}^{-1}$, i.e. near the value in eq. 10 and clearly 
the shallowest slope of all equilibrium curves.

The use of specific volumes obtained at ordinary pressure is validated by a reported density increase of approximately $5 \%$ between 0 and $0.5 \mathrm{GPa}$ for form II. ${ }^{8}$ Triple point III-III is found at about $0.1 \mathrm{GPa}$, thus it can be safely assumed that the decrease in the specific volumes of the three solid phases is in the order of $1 \%$.

\subsection{Triple points I-III-liq and II-III-liq}

The coordinates of triple point I-III-liq in the $P, T$ diagram of piracetam can be most easily found by setting the equations for the equilibria I-III and III-liq (6c and 7c) equal. These two equilibria are experimentally better defined than the I-liq equilibrium curve. The coordinates of triple point I-III-liq are found to be $T_{\text {I-III-liq }}=443.5 \mathrm{~K}$ and $P_{\text {I-III-liq }}=153$ MPa.

For the II-III-liq triple point, the intersection of curves II-III and III-liq, the $P, T$ coordinates are found by setting equations 10 (II-III) and 7c (III-liq) equal: $T_{\text {II-III-liq }}=436$ $\mathrm{K}$ and $P_{\text {II-III-liq }}=117 \mathrm{MPa}$. This is lower in temperature as well as in pressure than the coordinates of triple point I-III-liq.

\subsection{II-liq melting curve and triple point I-II-liq}

The melting point of form II (or triple point II-liq-vap if the melting takes place under saturated vapor pressure) has not yet been determined convincingly, as a clear melting peak in the DSC has never been observed. An estimate can be obtained by determining the slope of the II-liq equilibrium at the triple point II-III-liq (which has just been obtained) and by extrapolating the obtained expression of the II-liq equilibrium downwards to its saturating vapor pressure. Approximating the equilibrium curve by a straight line, $\mathrm{d} P / \mathrm{d} T$ can be determined following the same procedure as used above for the II-III equilibrium line. At triple point II-III-liq, equalities $\Delta_{\mathrm{II} \rightarrow \mathrm{liq}} S=\Delta_{\mathrm{III} \rightarrow \mathrm{liq}} S-\Delta_{\mathrm{III} \rightarrow \mathrm{II}} S$ and $\Delta_{\text {II } \rightarrow \text { liq } V}=\Delta_{\text {III } \rightarrow \text { liq } V}-\Delta_{\text {III } \rightarrow \text { II } V}$ hold. Because both enthalpy and volume changes for the melting of form III appeared to depend slightly on the temperature and pressure (see data in Table S8), their values have been calculated with equations S8a and S8b (derived from Table S8). $\Delta_{\mathrm{III} \rightarrow \mathrm{II}} S=0.01 \mathrm{~J} \mathrm{~K}^{-1} \mathrm{~g}^{-1}$ (section 4.2) and $\Delta_{\mathrm{III} \rightarrow \mathrm{liq}} S=0.48 \mathrm{~J} \mathrm{~K}^{-1} \mathrm{~g}^{-1}$ (eq. S8a evaluated at triple point II-III-liq) give $\Delta_{\mathrm{II} \rightarrow \mathrm{liq} S}=0.47 \mathrm{~J} \mathrm{~K}^{-1} \mathrm{~g}^{-1}$, while $\Delta_{\mathrm{III} \rightarrow \mathrm{II} V}=0.01030 \mathrm{~cm}^{3}$ $\mathrm{g}^{-1}$ (section 4.2) and $\Delta_{\mathrm{III} \rightarrow \text { liq } V}=0.10535 \mathrm{~cm}^{3} \mathrm{~g}^{-1}$ (eq. S8b evaluated at triple point II-III-liq) result in $\Delta_{\mathrm{II} \rightarrow \text { liq }} V=0.09505 \mathrm{~cm}^{3} \mathrm{~g}^{-1}$. Thus, $\mathrm{d} P / \mathrm{d} T_{\mathrm{II} \rightarrow \text { liq }}=0.47 / 0.09505=4.94 \mathrm{MPa} \mathrm{K}^{-1}$, and with $P_{\mathrm{II}-\mathrm{III}-\mathrm{liq}}=117 \mathrm{MPa}$ and $T_{\mathrm{II}-\mathrm{III}-\mathrm{liq}}=436 \mathrm{~K}$, the linear equation for curve II-liq becomes: 
$P_{\mathrm{II}-\mathrm{liq}}=-2040+4.94 T$

This equation gives $T_{\text {II-liq-vap }}=413 \mathrm{~K}$ at $P=0 \mathrm{MPa}$. This value, slightly higher than $T_{\text {III-liq- }}$ vap $=412.34 \mathrm{~K}$ (see Table 3 ), is in close agreement with the observation of KuhnertBrandstätter et al. by optical microscopy that the melting of crystals assumed to be forms II and III occurred at $415.5 \mathrm{~K}$ and $413 \mathrm{~K}$, respectively. ${ }^{3}$

The triple point I-II-liq is the intersection of equilibrium curves I-II, I-liq, and II-liq. Setting eqs. $5 \mathrm{c}$ and $11 \mathrm{a}$ equal for curves I-liq and II-liq, respectively, the triple point coordinates $T_{\mathrm{I}-\mathrm{II}-\mathrm{liq}}=450 \mathrm{~K}$ and $P_{\mathrm{I}-\mathrm{II}-\mathrm{liq}}=182 \mathrm{MPa}$ are obtained. A second combination of equations 5a (I-liq) and 8a (I-II) from PTA data only leads to the coordinates $T_{\text {I-II-liq }}=459$ $\mathrm{K}$ and $P_{\mathrm{I}-\mathrm{II}-\mathrm{liq}}=207 \mathrm{MPa}$, i.e. higher but still comparable to the foregoing results. Finally, using eqs. $8 \mathrm{a}$ and $11 \mathrm{a}$ (II-liq), $T_{\mathrm{I}-\mathrm{II}-\mathrm{liq}}=451 \mathrm{~K}$ and $P_{\mathrm{I}-\mathrm{II}-\mathrm{liq}}=186 \mathrm{MPa}$ are found, which is also near the previous values. Moreover in all cases, the triple point coordinates are higher than those of triple point I-III-liq.

\subsection{Construction of the complete P-T diagram}

A phase diagram involving three crystalline forms possesses ten triple points irrespective of their relative stabilities. ${ }^{32}$ Three triple points, I-liq-vap, II-liq-vap, and IIIliq-vap, are located on the liq-vap equilibrium, the saturating vapor pressure of the liquid. This equilibrium separates the phase diagram into a high-pressure and a lowpressure part. In the low-pressure domain, three more triple points are located, I-II-vap, I-III-vap, and II-III-vap, all part of the condensed-phase - vapor equilibria. In the highpressure domain, another four triple points, I-II-III, I-II-liq, I-III-liq, and II-III-liq are located.

\subsubsection{Regions involving only condensed phases}

Using the results obtained or inferred from PTA and HP-DTA experiments, the diagram shown in Figure 5 represents the high-pressure domain with the condensed phases. It is important to realize that an equilibrium curve passing through a triple point must change its stability level. In fact, around a triple point, the stability ranking must alternate for each equilibrium line, as can be seen for triple point I-II-III, where line 4 below is stable, line 5 is metastable (broken line), line 6 is stable, continuing clockwise, equilibrium 4 is encountered again, which is now metastable etc. This fact, which is due 
to the intersecting Gibbs energy surfaces of which the pressure-temperature phase diagram is a projection, is called the alternation rule. ${ }^{33,34}$ The alternation of the twophase equilibria around the different triple points can be clearly observed in Figure 5a. Once the stability rank of one of the triple points has been determined, the ranks of the others are defined and therefore also those of the different two-phase equilibria. The result is presented in Figure 5.

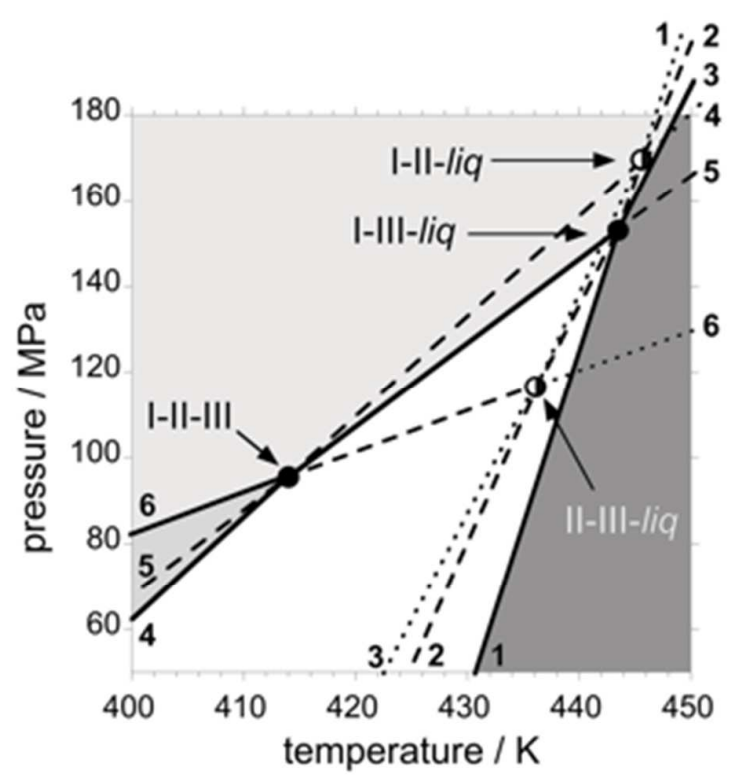

Figure 5a. Location of the triple points in the $P$ - $T$ region involving only condensed phases. Two-phase equilibrium curves: 1: I-liq, 2: II-liq, 3: III-liq, 4: I-II, 5: I-III, and 6: IIIII. Filled circles: stable triple points, half-filled circles: metastable triple points. Solid lines: stable equilibria, dashed lines: metastable equilibria, dotted lines: super metastable equilibria. Stable phase regions: dark grey: liquid, white: form I, medium grey: form II, light grey: form III.

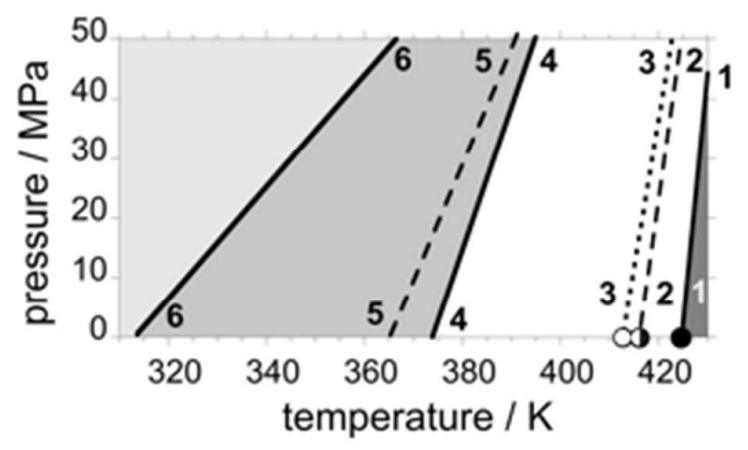

Figure 5b. Detail of the P-T diagram with the three triple points along the liq-vap curve (= x-axis): solid circle: I-liq-vap, stable, half-filled circle: II-liq-vap, metastable, open 
circle: III-liq-vap, super-metastable. The diagram shows the same two-phase equilibrium lines as in Figure 5a. Stable phase regions: see Figure 5a.

The results presented in Figure 5 and obtained by high-pressure measurements and thermodynamic inferences can be compared to a phase diagram obtained by the topological method based on the Clapeyron equation and the assumption that all twophase equilibria can be represented by straight lines in a $P$ - $T$ diagram. ${ }^{24,26,35-38}$

The $\mathrm{d} P / \mathrm{d} T$ slopes of the $P$ - $T$ melting curves can be calculated using the enthalpy and volume changes at ordinary pressure $(\mathrm{P}=0 \mathrm{MPa}$ ) from DSC data (Table 3 ) and specific volume measurements (equations 1 to $4 \mathrm{a}$ ). This results in $\mathrm{d} P / \mathrm{d} T_{\mathrm{I}-\text { liq }}=4.80 \mathrm{MPa} \mathrm{K}^{-1}$ and $\mathrm{d} P / \mathrm{d} T_{\text {III-liq }}=3.89 \mathrm{MPa} \mathrm{K}^{-1}$ and leads to the following equations $(P$ in $\mathrm{MPa}, T$ in $\mathrm{K}$, the subscript $\mathrm{T}$ in the equation number indicates "topological"):

$\mathrm{P}_{\mathrm{I}-\mathrm{liq}}=-2037+4.80 T$

and

$P_{\text {III-liq }}=-1604+3.89 T$

for lines I-liq and III-liq, which intersect at $T_{\text {I-III-liq }}=477 \mathrm{~K}$ and $P_{\text {I-III-liq }}=252 \mathrm{MPa}$. This is higher than the coordinates obtained through the high-pressure data points (section 4.3); however, it leads to the same topological picture of two converging equilibrium lines with increasing pressure.

Because the III-I equilibrium curve also passes through triple point I-III-liq its equation ( $P$ and $T$ in $\mathrm{MPa}$ and $\mathrm{K}$ respectively)

$P_{\text {III-I }}=-315+1.187 T$

has been determined using the mean value $\Delta_{\mathrm{III} \rightarrow l} h=27.5 \mathrm{~J} \mathrm{~g}^{-1}$ (Table 3 ) and $\Delta_{\text {III } \rightarrow \text { I }} V=$ $0.0486 \mathrm{~cm}^{3} \mathrm{~g}^{-1}$ at $477 \mathrm{~K}$ (eqs. 1 and 3 ). Eq. $7_{\mathrm{T}}$ leads to the transition point I-III at ordinary pressure of $T_{\text {I-III-vap }}=266 \mathrm{~K}$ at $P=0 \mathrm{MPa}$.

The experimental melting point of the II-liq equilibrium reported in the literature has not convincingly been determined. Nevertheless, if $T_{\mathrm{II}_{\rightarrow} \text { liq }}=413 \mathrm{~K}$ is used together with 
$\Delta_{\mathrm{II} \rightarrow \text { liq }} h=211.5 \mathrm{~J} \mathrm{~g}^{-1}$ (the algebraic sum $\Delta_{\mathrm{II} \rightarrow \mathrm{I}} h+\Delta_{\mathrm{I} \rightarrow \text { liq }} h=24.4+187.1$ ) and the volume change on melting, $0.1184 \mathrm{~cm}^{3} \mathrm{~g}^{-1}$ calculated with equations 2 and $4 \mathrm{~b}$ (at $413 \mathrm{~K}$ ), $\mathrm{d} P / \mathrm{d} T_{\mathrm{II}}$ liq becomes $4.32 \mathrm{MPa} \mathrm{K}^{-1}$. This leads to the following relation for the melting curve of form II ( $P$ in $\mathrm{MPa}$ and $T$ in $\mathrm{K})$ :

$P_{\mathrm{II}-\mathrm{liq}}=-1786+4.32 \mathrm{~T}$

Although this value of $\mathrm{d} P / \mathrm{d} T_{\text {II-liq }}$ is different from that reported in section 4.4 , the topological method leads to the same inequality in the slopes of the melting equilibria (III-liq < II-liq < I-liq).

The coordinates of the "topological" triple points I-II-liq, I-III-liq and II-III-liq calculated with equations $5_{\mathrm{T}}, 6_{\mathrm{T}}$ and $11_{\mathrm{T}}$ are compiled in Table 4 and compared with the values obtained or inferred from the high-pressure data.

If the literature value of $415 \mathrm{~K}$ is used for $T_{\mathrm{II}-\text { liq, }}$ equation $11_{\mathrm{T}}$ becomes

$P_{\mathrm{II}-\mathrm{liq}}=-1769+4.26 T$

which leads in combination with equations $5_{\mathrm{T}}$ and $6_{\mathrm{T}}$, to the same inequalities $T_{\mathrm{I}-\mathrm{II}-\mathrm{liq}}>T_{\mathrm{I}}$ III-liq and $\mathrm{P}_{\mathrm{I}-\mathrm{II}-\mathrm{liq}}>\mathrm{P}_{\mathrm{I}-\mathrm{III}-\mathrm{liq}}$ (Table 4). Clearly the melting point of form II must be located in between those of forms I and III and it can thus be concluded that topological tools to construct a phase diagram can be a powerful means to verify and complete a phase diagram partially obtained by experimental data.

Table 4. Triple point coordinates I-II-liq, I-III-liq and II-III-liq determined directly from high-pressure data and by the Clapeyron equation (topological approach)

\begin{tabular}{|l|l|l|l|l|l|l|}
\hline & \multicolumn{3}{|l|}{ I-II-liq } & \multicolumn{2}{l|}{ I-III-liq } & \multicolumn{2}{l|}{ II-III-liq } \\
\hline & P/MPa & $T / \mathrm{K}$ & $P / \mathrm{MPa}$ & $T / \mathrm{K}$ & $P / \mathrm{MPa}$ & $T / \mathrm{K}$ \\
\hline High-pressure data & 182 & 450 & 153 & 443 & 117 & 436 \\
\hline $\begin{array}{l}\text { Topological data with } \\
\text { TII-liq = 413 K }\end{array}$ & 501 & 529 & 250 & 477 & 27 & 419 \\
\hline $\begin{array}{l}\text { Topological data with } \\
\text { TII-liq = 415 K }\end{array}$ & 361 & 500 & 250 & 477 & 120 & 443 \\
\hline
\end{tabular}




\subsubsection{Triple points involving the vapor phase}

Lines 4, 5 and 6 cross respectively triple points I-II-vap, I-III-vap and II-III-vap where the vapor pressure is the saturating vapor pressure of the involved condensed phases at the respective triple points. Their pressure coordinates can be approximately determined with the experimental vapor pressure results for form II obtained by Picciochi et al. ${ }^{4}$ These vapor pressures in the temperature range of $356.66 \mathrm{~K}$ to $374.44 \mathrm{~K}$ have been fitted with the Clausius-Clapeyron equation, leading to the following expression $(P$ in pascal, $T$ in kelvin):

$\ln \left(P_{\mathrm{II}-\mathrm{vap}}\right)=36.7-(14143 / T) \quad r^{2}=0.996$

From eq. 12 , an average sublimation enthalpy is obtained $\Delta_{\mathrm{II} \rightarrow \mathrm{vap}} H=14143 R$ (the gas constant $\left.R=8.3145 \mathrm{~J} \mathrm{~K}^{-1} \mathrm{~mol}^{-1}\right)$, which equals $117.6 \mathrm{~kJ} \mathrm{~mol}^{-1}\left(827.2 \mathrm{~J} \mathrm{~g}^{-1}\right)$.

At the temperature of the triple point I-II-vap, $373 \mathrm{~K}$, the vapor pressure of form I equals that of form II. Thus, with $\Delta_{\mathrm{I} \rightarrow \mathrm{vap}} H=\Delta_{\mathrm{II} \rightarrow \mathrm{vap}} H-\Delta_{\mathrm{II} \rightarrow \mathrm{I}} H=117592-3462=114130 \mathrm{~J} \mathrm{~mol}^{-1}$, the vapor pressure of form I is given by $(\mathrm{P} / \mathrm{Pa}, T / \mathrm{K})$ :

$\ln \left(\mathrm{P}_{\mathrm{I}-\mathrm{vap}}\right)=35.6-(13727 / T)$

This leads to a vapor pressure of $26 \mathrm{~Pa}$ at the melting point of form I or triple point $T_{\text {I-liq-vap }}=424.5 \mathrm{~K}$.

At the temperature of triple point II-III-vap, $316 \mathrm{~K}$, the vapor pressure of form III equals that of form II. Thus, with $\Delta_{\mathrm{III} \rightarrow \text { vap }} H=\Delta_{\mathrm{II} \rightarrow \mathrm{vap}} H+\Delta_{\mathrm{II} \rightarrow \mathrm{III}} H=117592+441=118033 \mathrm{~J} \mathrm{~mol}^{-1}$, the vapor pressure of form III is given by $(P / \mathrm{Pa}, T / \mathrm{K})$ :

$\ln \left(P_{\text {III-vap }}\right)=36.9-(14196 / T)$

The vapor pressure of form I at the temperature $\left(T_{\text {I-liq }}=424.46 \mathrm{~K}\right)$ of triple point I-liqvap is the same as the vapor pressure of the liquid phase. With $\Delta_{\text {liq } \rightarrow \text { vap }} H=\Delta_{\mathrm{I} \rightarrow \mathrm{vap}} H$ $\Delta_{\mathrm{I} \rightarrow \mathrm{liq}} H=114130-26598=87532 \mathrm{~J} \mathrm{~mol}^{-1}$, this leads to $(P / \mathrm{Pa}, T / \mathrm{K}):$

$\ln \left(P_{\text {liq-vap }}\right)=28.0-(10528 / T)$ 
Eq. 15 gives a vapor pressure of $12 \mathrm{~Pa}$ at $T_{\mathrm{III}-\mathrm{liq}}=412.3 \mathrm{~K}$.

By setting eqs. (12) and (15) equal, the pressure and temperature of the melting triple point of form II can be found: $P=17.3 \mathrm{~Pa}$ and $T=418 \mathrm{~K}$, i.e. greater than $T_{\text {III-liq }}$ and close to the values of $413 \mathrm{~K}$ (see above) and $415 \mathrm{~K}^{3}$ (If $T_{\mathrm{II}-\mathrm{liq}}=413 \mathrm{~K}$ is used, the vapor pressure is found to be $11.7 \mathrm{~Pa}$ with equation 12 ).

The last vapor pressure to be determined is the vapor pressure at triple point I-III-vap, whose temperature was found to be $362 \mathrm{~K}$ from PTA experiments. By setting equal equations 13 and 14, the temperature of this triple point (at which the vapor pressure of the two forms should be equal) is found to be $360.8 \mathrm{~K}$ (i.e. the same value as $362 \mathrm{~K}$, the difference is due to rounding). Using either of equations 13 and 14, the vapor pressure is found to be $\approx 0.1 \mathrm{~Pa}$, slightly greater than the vapor pressure of form II of $0.093 \mathrm{~Pa}$ found with equation 12 (at $362 \mathrm{~K}$ ), thus indicating that, at $362 \mathrm{~K}$, the I-III-vap triple point is metastable with respect to the II-vap equilibrium. The results can be summarized topologically by representing the exponential curves as straight lines; the relative positions of the triple points involving the vapor phase are depicted in Figure 6.

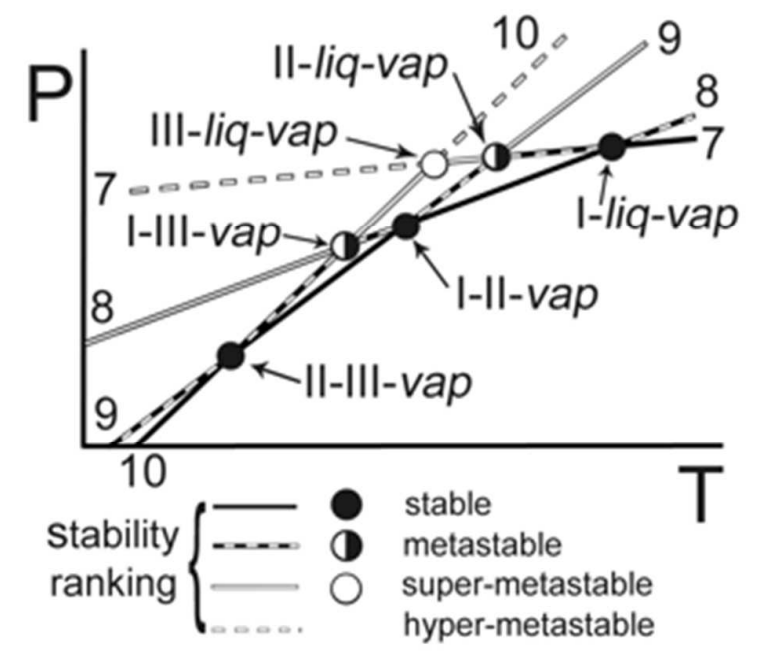

Figure 6. Topological representation of the two-phase equilibria involving the vapor phase in the $P-T$ diagram of piracetam: 7 = liquid-vapor equilibrium, $8=$ I-vapor, $9=\mathrm{II}-$ vapor, $10=$ III-vapor 


\section{Concluding remarks}

Piracetam polymorphism is a case that clearly demonstrates how delicate the determination of the stability hierarchy of polymorphs can be, in particular if only transition temperature inequalities are used. Moreover, when a melting temperature is not known, the case becomes even more difficult.

It has been demonstrated how the stability hierarchy of forms I, II, and III was inferred from experimental results that do not rely on the measured solid-solid transition temperatures by DSC; the latter are heating-rate dependent and randomly distributed in relation to each other. High-pressure measurements (isothermal pressure dependent, and isobaric temperature dependent) provided the I-II-III triple point and the two equilibria II-I and III-I with which the position of the third solid-solid equilibrium III-II could be determined.

The inequalities between the slopes of the solid-solid equilibrium curves involving forms I, II and III were experimentally obtained and obey the sequence $\mathrm{d} P / \mathrm{d} T_{\text {I-II }}>$

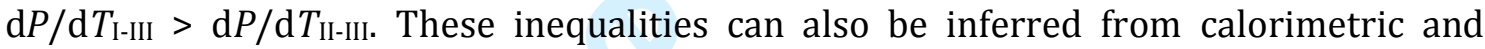
volumetric data obtained at "ordinary" pressure, thus without explicit high-pressure measurements. Independent of the temperature coordinate, the inequality in the slopes can be calculated using the Clapeyron equation with the enthalpies of transition in J g-1 from Table $3\left(\Delta_{\mathrm{II} \rightarrow \mid} h=24.4, \Delta_{\mathrm{III} \rightarrow \mid} h=27.5\right.$ and inferred $\left.\Delta_{\mathrm{III} \rightarrow \mathrm{II}} h=3.1\right)$ and with the differences in the specific volumes in $\mathrm{cm}^{3} \mathrm{~g}^{-1}$ at for instance $100 \mathrm{~K}, 300 \mathrm{~K}$ and $500 \mathrm{~K}$ using equations 1, 2 and 3 . In each case, one finds $T\left(\mathrm{~d} P / \mathrm{d} T_{\text {I-II }}\right)>T\left(\mathrm{~d} P / \mathrm{d} T_{\text {I-III }}\right)>T$ $\left(\mathrm{d} P / \mathrm{d} T_{\text {II-III }}\right.$ ) (see calculations in Table $\mathrm{S} 11$ in the supporting information). These three slopes will intersect at a single temperature, the triple point I-II-III, which leads to the unambiguous conclusion that the inequality in the temperatures of triple points I-II-vap, I-III-vap and II-III-vap (i.e. at $P=0 \mathrm{MPa}$ ) must be $T_{\text {I-II-vap }}>T_{\text {I-III-vap }}>T_{\text {II-III-vap, without }}$ resorting to the temperatures found by DSC for transitions II $\rightarrow$ I and III $\rightarrow \mathrm{I}$.

To conclude, the $P$ - $T$ diagram for the phase relationships involving the three solid forms (I, II, and III) of piracetam can be topologically drawn as presented in figure $7 \mathrm{a}$, in which all two-phase equilibria are present, or in figure $7 \mathrm{~b}$ in which only stable equilibria and subsequent stable phase regions are present. On increasing the pressure, forms I and II both transform to form III, which is the stable phase at low temperature, including room temperature $(<316 \mathrm{~K})$, and high pressure. Thus, the conclusion from previous studies 
that form III is the stable form at room temperature ${ }^{3-5}$ has been correct, but for the wrong reasons. Moreover, a stable domain for form II was in most cases overlooked (Figure 7b).

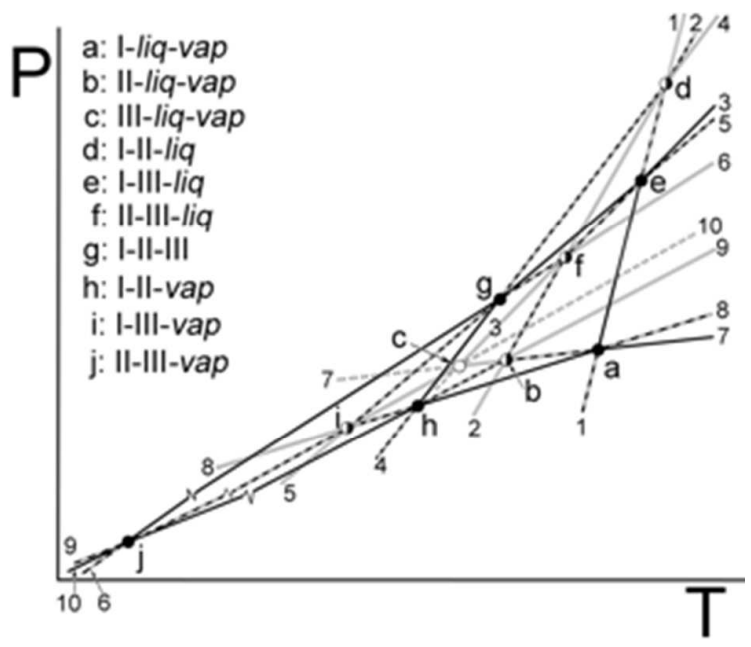

Figure 7a. Complete topological $P-T$ diagram for the phase relationships involving forms I, II and III of piracetam. Two-phase equilibrium curves: same numbering as in Figures 5 and 6. Stability ranking: same as in figure 6.

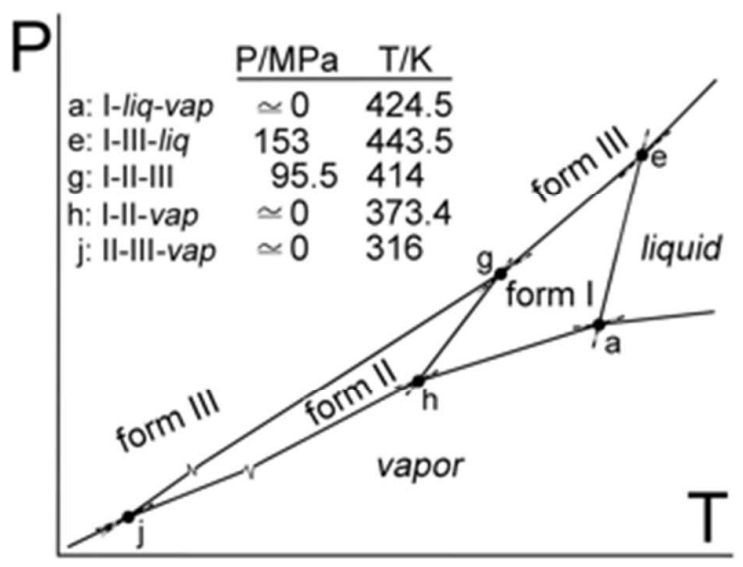

Figure 7b. Topological representation of the stable $P$ - $T$ diagram. The stable phase regions are shown and delimited by the equilibrium curves connecting the five stable triple points (from ten in total). Form III is stable under ambient conditions.

\section{Acknowledgements}

The authors thank Mr G. Marsolier, formerly at the Laboratoire de Chimie du Solide et 
Inorganique Moléculaire, Université de Rennes I, France, for assistance with the powderdiffraction data collection. This work has been supported by the Spanish Ministry of Science and Innovation (grant FIS2014-54734-P) and the Catalan Government (grant 2014 SGR-581).

\section{References}

1. Buerger MJ. 1951. Crystallographic aspects of phase transformations. In Smoluchowski R, editor Phase transformations in solids, ed., New York: Wiley. p 183211.

2. Buerger MJ 1972. Phase transformations. Sov Phys Crystallogr 16(6):959-968.

3. Kuhnert-Brandstätter M, Burger A, Völlenklee R 1994. Stability behavior of piracetam polymorphs. Sci Pharm 62:307-316.

4. Picciochi R, Diogo HP, Minas da Piedade ME 2011. Thermodynamic characterization of three polymorphic forms of piracetam. J Pharm Sci 100:594-603.

5. Maher A, Seaton CC, Hudson S, Croker DM, Rasmuson AC, Hodnett BK 2012. Investigation of the solid-state polymorphic transformations of piracetam. Cryst Growth Des 12:6223-6233.

6. Céolin R, Agafonov V, Louër D, Dzyabchenko VA, Toscani S, Cense JM 1996. Phenomenology of polymorphism .3. p,T diagram and stability of piracetam polymorphs. J Solid State Chem 122(1):186-194.

7. Fabbiani FPA, Allan DR, Parsons S, Pulham CR 2005. An exploration of the polymorphism of piracetam using high pressure. CrystEngComm 7(29):179-186. 8. Fabbiani FPA, Allan DR, David WIF, Davidson AJ, Lennie AR, Parsons S, Pulham CR, Warren JE 2007. High-pressure studies of pharmaceuticals: an exploration of the behavior of piracetam. Cryst Growth Des 7:1115-1124.

9. Louër D, Louër M, Dzyabchenko VA, Agafonov V, Céolin R 1995. Structure of a metastable phase of piracetam from X-ray powder diffraction using the atom-atom potential method. Acta Crystallographica, Section B: Structural Science 51:182-187.

10. Admiraal G, Eikelenboom JC, Vos A 1982. Structure of the triclinic and monoclinic modifications of (2-oxo-1-pyrrolidinyl)acetamide. Acta Crystallographica, Section B: Structural Science 38:2600-2605.

11. Chambrier M-H, Bouhmaida N, Bonhomme F, Lebegue S, Gillet J-M, Jelsch C, Ghermani NE 2011. Electron and electrostatic properties of three crystal forms of piracetam. Cryst Growth Des 11:2528-2539.

12. Bandoli G, Clemente DA, Grassi A, Pappalardo GC 1981. Molecular determinants for drug-receptor interactions 1 . solid-state structure and conformation of the novel nootropic agent 2-pyrrolidone-N-acetamide: X-ray and theoretical SCF-MO studies. Mol Pharmacol 20(3):558-564.

13. Galdecki Z, Glowka ML 1983. Crystal structure of nootropic agent piracetam: 2oxopyrrolidin-1-ylacetamide. Pol J Chem 57:1307-1312.

14. Tilborg A, Jacquemin D, Norberg B, Perpete E, Michaux C, Wouters J 2011.

Structural study of piracetam polymorphs and cocrystals: crystallography redetermination and quantum mechanic calculations. Acta Crystallographica, Section B: Structural Science 67:499-507. 
15. Maher A, Rasmuson AC, Croker DM, Hodnett BK 2012. Solubility of the metastable polymorph of piracetam (form II) in a range of solvents. J Chem Eng Data 57:3525-3531. 16. Roisnel T, Rodriguez-Carvajal J 2001. WinPLOTR: A Windows tool for powder diffraction pattern analysis. Epdic 7: European Powder Diffraction, Pts 1 and 2 3783:118-123.

17. Louër D, Boultif A 2014. Some further considerations in powder diffraction pattern indexing with the dichotomy method. Powder Diffr 29(S2):S7-S12.

18. Rodriguez-Carvajal J 1993. Recent advances in magnetic structure determination by neutron powder diffraction. Physica B 192:55-69.

19. Petit JC, Ter Minassian L 1974. Measurements of $(\partial \mathrm{V} / \partial \mathrm{T})_{\mathrm{p}},(\partial \mathrm{V} / \partial \mathrm{p})_{\mathrm{T}}$, and $(\partial$ H/ $\partial \mathrm{T}$ ) by flux calorimetry. J Chem Thermodyn 6:1139-1152.

20. Ter Minassian L, Pruzan P 1977. High-pressure expansivity of materials determined by piezo-thermal analysis. J Chem Thermodyn 9:375-390.

21. Ter Minassian L, Milliou F 1992. New developments in the field of piezothermal analysis. An experimental approach to the solid state transitions in the case of n-alkanes C21, C23 and C25. J Therm Anal 38(1-2):181-196.

22. Ter Minassian L, Toscani S 1999. The (p,T) thermodynamic behavior of $n-$ alkanoic acids absorbed on silicate glass: Characterization of the phase transitions. J Phys Chem B 103:11105-11113.

23. Würflinger A 1975. Differential thermal-analysis under high-pressure IV. Lowtemperature DTA of solid-solid and solid-liquid transitions of several hydrocarbons up to 3 kbar. Ber Bunsen-Ges Phys Chem 79(12):1195-1201.

24. Barrio M, Maccaroni E, Rietveld IB, Malpezzi L, Masciocchi N, Ceolin R, Tamarit J-L 2012. Pressure-temperature state diagram for the phase relationships between benfluorex hydrochloride forms I and II: A case of enantiotropic behavior. J Pharm Sci 101(3):1073-1078.

25. Gana I, Barrio M, Ghaddar C, Nicolai B, Do B, Tamarit JL, Safta F, Rietveld IB 2015. An integrated view of the influence of temperature, pressure, and humidity on the stability of trimorphic cysteamine hydrochloride. Mol Pharmaceut 12:2276-2288. 26. Rietveld IB, Barrio M, Tamarit J-L, Nicolai B, Van de Streek J, Mahe N, Ceolin R, Do B 2011. Dimorphism of the Prodrug L-Tyrosine Ethyl Ester: Pressure-Temperature State Diagram and Crystal Structure of Phase II. J Pharm Sci 100(11):4774-4782.

27. Gavezzotti A. 2013. Molecular Aggregation. Structure Analysis and Molecular Simulation of Crystals and Liquids. Oxford, UK: Oxford University Press. p 277. 28. Ceolin R, Rietveld IB 2015. The topological pressure-temperature phase diagram of ritonavir, an extraordinary case of crystalline dimorphism. Ann Pharm Fr 73(1):2230.

29. Rietveld IB, Ceolin R 2015. Phenomenology of crystalline polymorphism: overal monotropic behavior of the cardiotonic agent FK664 forms A and B. J Therm Anal Calorim.

30. Ceolin R, Rietveld IB 2010. Phenomenology of polymorphism and topological pressure-temperature diagrams. J Therm Anal Calorim 102(1):357-360.

31. Mahe N, Perrin M, Barrio M, Nicolai B, Rietveld I, Tamarit J, Ceolin R 2011. SolidState Studies of the Triclinic ( $\left.\mathrm{Z}^{\prime}=2\right)$ Antiprotozoal Drug Ternidazole. J Pharm Sci 100(6):2258-2266.

32. Riecke E 1890. Spezielle Fälle von Gleichgewichterscheinungen eines aus mehreren Phasen zusammengesetzten Systemes. Z Phys Chem (Munich) 6:411. 33. Oonk HAJ. 1981. Phase theory, The thermodynamics of heterogeneous equilibria. Amsterdam: Elsevier Scientific Publishing Company. 
34. Oonk HAJ, Calvet MT. 2008. Equilibrium between phases of matter, Phenomenology and Thermodynamics. Dordrecht (NL): Springer.

35. Rietveld I, Barrio M, Espeau P, Tamarit J, Ceolin R 2011. Topological and

Experimental Approach to the Pressure-Temperature-Composition Phase Diagram of the Binary Enantiomer System d- and l-Camphor. J Phys Chem B 115(7):1672-1678.

36. Gana I, Ceolin R, Rietveld IB 2012. Phenomenology of polymorphism: The topological pressure-temperature phase relationships of the dimorphism of finasteride. Thermochim Acta 546:134-137.

37. Gana I, Barrio M, Do B, Tamarit J-L, Ceolin R, Rietveld IB 2013. Benzocaine polymorphism: Pressure-temperature phase diagram involving forms II and III. Int J Pharm 456(2):480-488.

38. Perrin M-A, Bauer M, Barrio M, Tamarit J-L, Ceolin R, Rietveld IB 2013.

Rimonabant dimorphism and its pressure-temperature phase diagram: A delicate case of overall monotropic behavior. J Pharm Sci 102(7):2311-2321. 


\section{Figure Captions}

Figure 1. Sublimation-condensation of piracetam crystals in a silica tube subjected to a temperature gradient for 6 days. The initial sample (form III) was placed in the small container on the left-hand side and maintained at $414 \mathrm{~K}$.

Figure 2. Onset temperatures of transitions II $\rightarrow$ I (solid squares), III $\rightarrow$ I (open circles) and melting of form I (solid diamonds) (A) of samples obtained by different methods and heated at 5 or $10 \mathrm{~K} \mathrm{~min}^{-1}$ (see for details Table S2 to S5) and (B) as a function of the heating rate.

Figure 3. Specific volumes of piracetam forms I (open circles, eq. 1), II (solid diamonds, eq. 2) and III (solid circles, eq. 3) as a function of temperature from high-resolution Xray powder diffraction and comparison with volumes from single crystal structures (a: ref ${ }^{8}, \mathrm{~b}$ and c: ref ${ }^{11}$ ). The experimental (eq. $4 \mathrm{a}$, open diamonds) and calculated (eq. $4 \mathrm{~b}$, dashed line, see text) specific volumes of liquid piracetam are also provided.

Figure 4. Pressure-temperature phase diagram of the phase transitions of piracetam with experimental data points only. Fusion of form I: squares, fusion of form III: diamonds, III $\rightarrow$ I: plus sign, $\mathrm{II} \rightarrow \mathrm{I}_{\mathrm{PTA}}$ : circles, and $\mathrm{II} \rightarrow \mathrm{I}_{\mathrm{HP}-\mathrm{DTA}}:$ triangles.

Figure 5a. Location of the triple points in the $P$ - $T$ region involving only condensed phases. Two-phase equilibrium curves: 1: I-liq, 2: II-liq, 3: III-liq, 4: I-II, 5: I-III, and 6: IIIII. Filled circles: stable triple points, half-filled circles: metastable triple points. Solid lines: stable equilibria, dashed lines: metastable equilibria, dotted lines: super metastable equilibria. Stable phase regions: dark grey: liquid, white: form I, medium grey: form II, light grey: form III.

Figure 5b. Detail of the P-T diagram with the three triple points along the liq-vap curve (= x-axis): solid circle: I-liq-vap, stable, half-filled circle: II-liq-vap, metastable, open circle: III-liq-vap, super-metastable. The diagram shows the same two-phase equilibrium lines as in Figure 5a. Stable phase regions: see Figure 5a.

Figure 6. Topological representation of the two-phase equilibria involving the vapor phase in the $P-T$ diagram of piracetam: 7 = liquid-vapor equilibrium, $8=$ I-vapor, $9=\mathrm{II}$ vapor, $10=$ III-vapor 
Figure 7a. Complete topological $P$ - $T$ diagram for the phase relationships involving forms I, II and III of piracetam. Two-phase equilibrium curves: same numbering as in Figures 5 and 6. Stability ranking: same as in figure 6.

Figure 7b. Topological representation of the stable $P$ - $T$ diagram. The stable phase regions are shown and delimited by the equilibrium curves connecting the five stable triple points (from ten in total). Form III is stable under ambient conditions. 


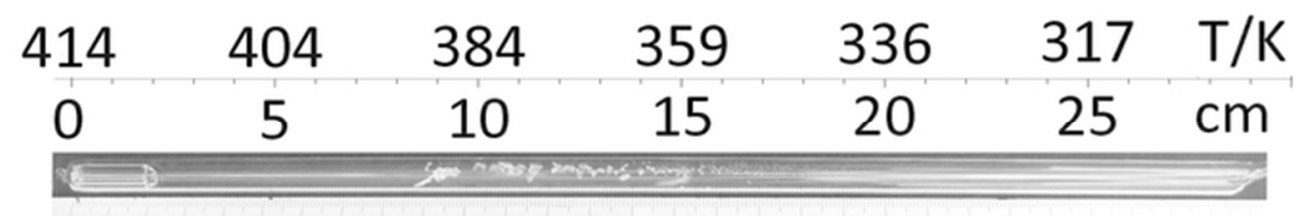

Figure 1. Sublimation-condensation of piracetam crystals in a silica tube subjected to a temperature gradient for 6 days. The initial sample (form III) was placed in the small container on the left-hand side and maintained at $414 \mathrm{~K}$ $28 \times 5 \mathrm{~mm}(600 \times 600 \mathrm{DPI})$

John Wiley \& Sons, Inc. 


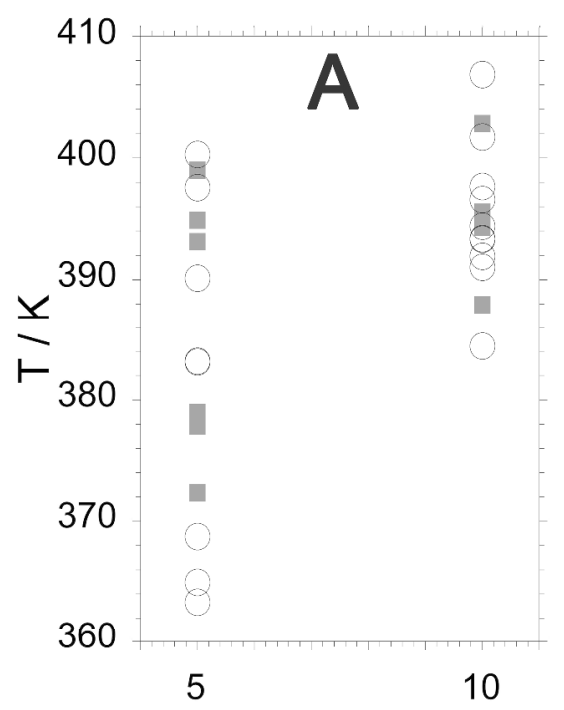

heating rate $/ \mathrm{K} \mathrm{min}^{-1}$

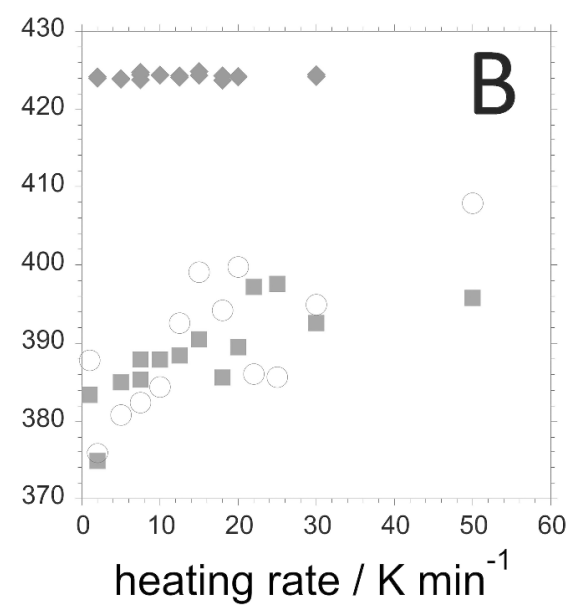

Figure 2. Onset temperatures of transitions II $\rightarrow$ I (solid squares), III $\rightarrow$ I (open circles) and melting of form I (solid diamonds) (A) of samples obtained by different methods and heated at 5 or $10 \mathrm{~K} \mathrm{~min}-1$ (see for details Table S2 to S5) and (B) as a function of the heating rate. $221 \times 615 \mathrm{~mm}(600 \times 600 \mathrm{DPI})$

John Wiley \& Sons, Inc. 
Figure 3. Specific volumes of piracetam forms I (open circles, eq. 1), II (solid diamonds, eq. 2) and III (solid circles, eq. 3) as a function of temperature from high-resolution X-ray powder diffraction and comparison with volumes from single crystal structures ( $a$ : ref $8, b$ and $c$ : ref 11 ). The experimental (eq. $4 a$, open diamonds) and calculated (eq. $4 \mathrm{~b}$, dashed line, see text) specific volumes of liquid piracetam are also provided.

$73 \times 66 \mathrm{~mm}(600 \times 600 \mathrm{DPI})$ 


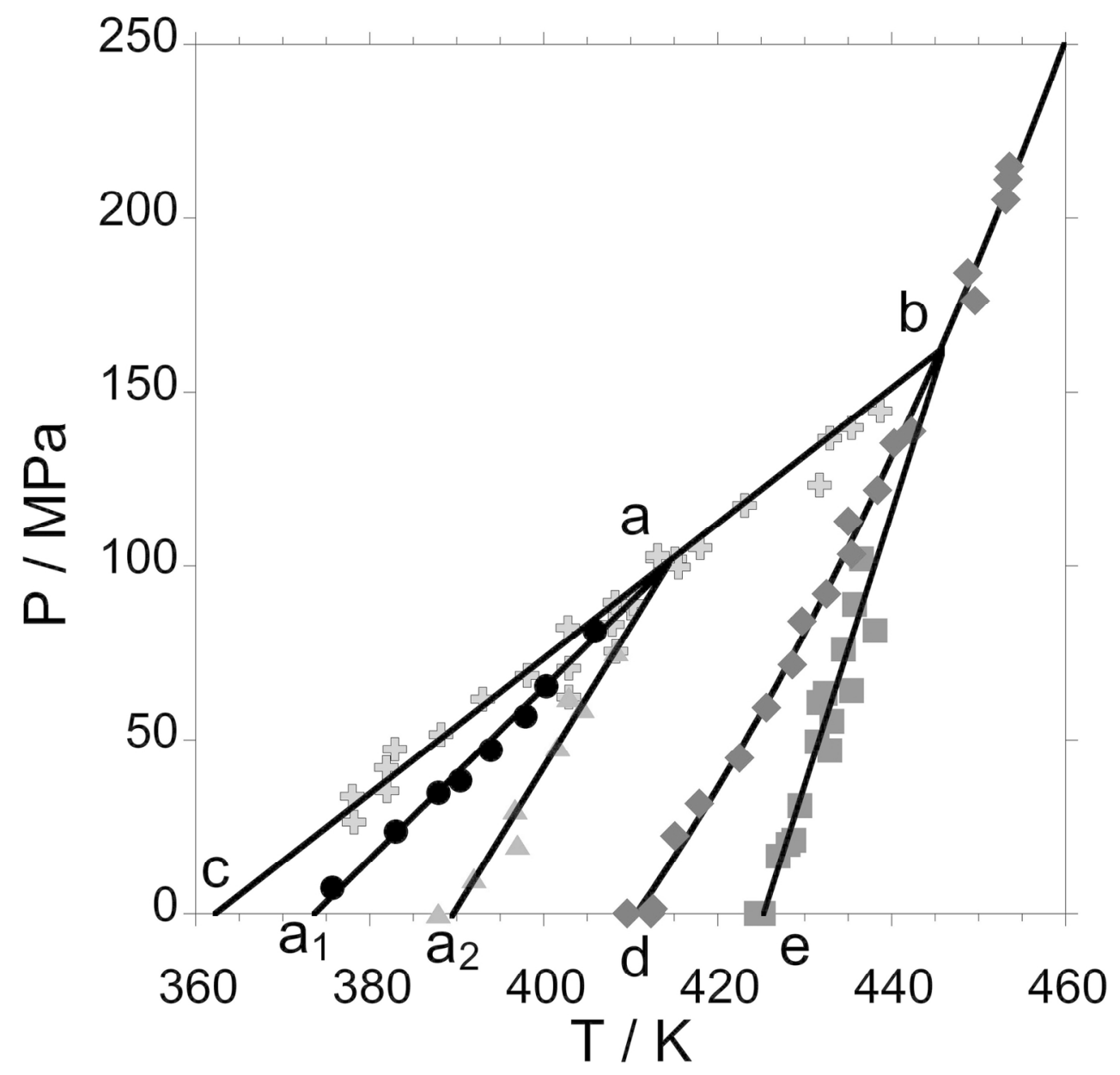

Figure 4. Pressure-temperature phase diagram of the phase transitions of piracetam with experimental data points only. Fusion of form I: squares, fusion of form III: diamonds, III $\rightarrow$ I: plus sign, II $\rightarrow$ IPTA: circles, and II $\rightarrow$ IHP-DTA: triangles. $79 \times 79 \mathrm{~mm}(600 \times 600 \mathrm{DPI})$ 


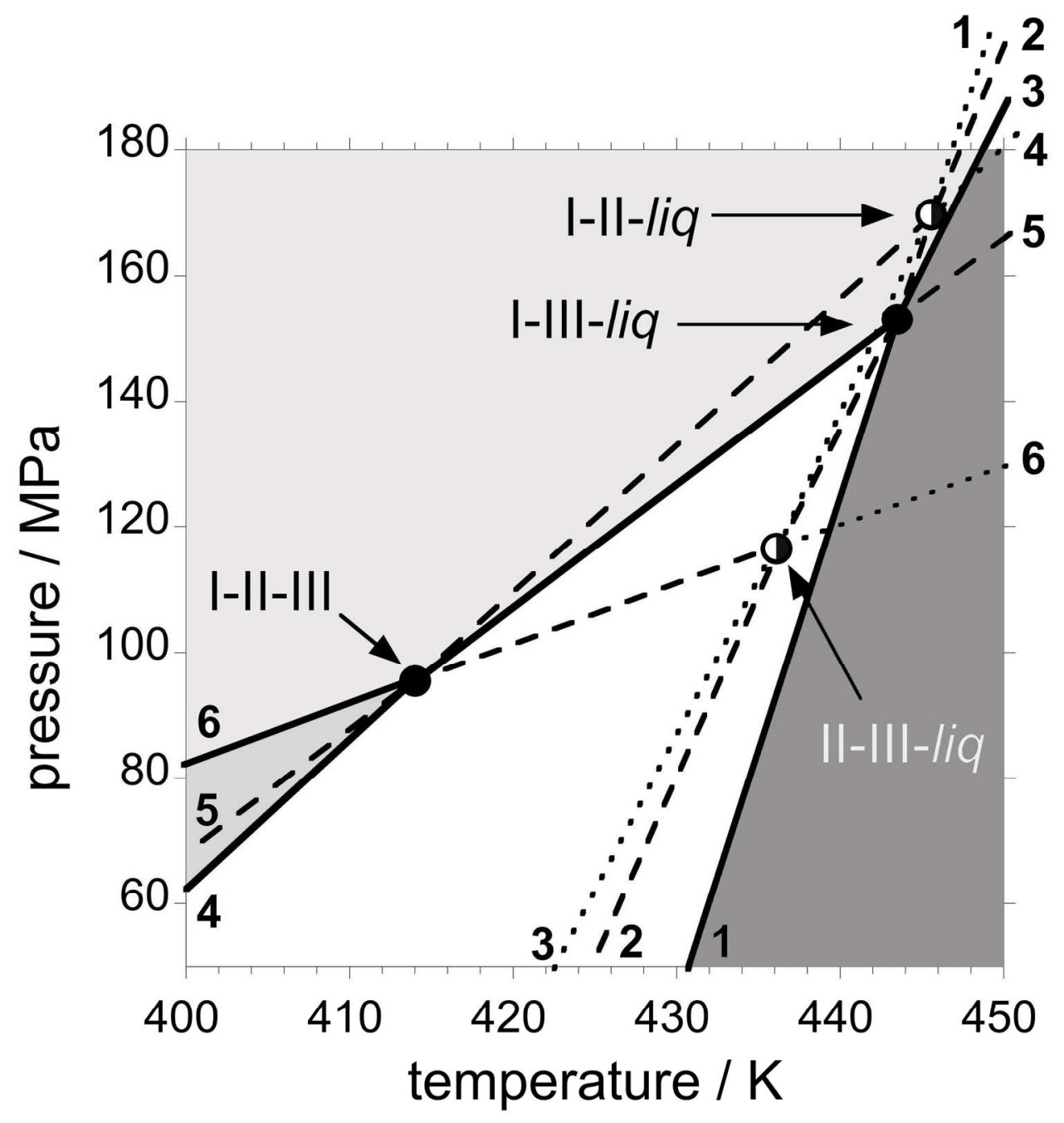

Figure 5a. Location of the triple points in the P-T region involving only condensed phases. Two-phase equilibrium curves: 1: I-liq, 2: II-liq, 3: III-liq, 4: I-II, 5: I-III, and 6: II-III. Filled circles: stable triple points, half-filled circles: metastable triple points. Solid lines: stable equilibria, dashed lines: metastable equilibria, dotted lines: super -metastable equilibria. Stable phase regions: dark grey: liquid, white: form I, medium grey: form II, light grey: form III. $84 \times 90 \mathrm{~mm}(600 \times 600 \mathrm{DPI})$ 


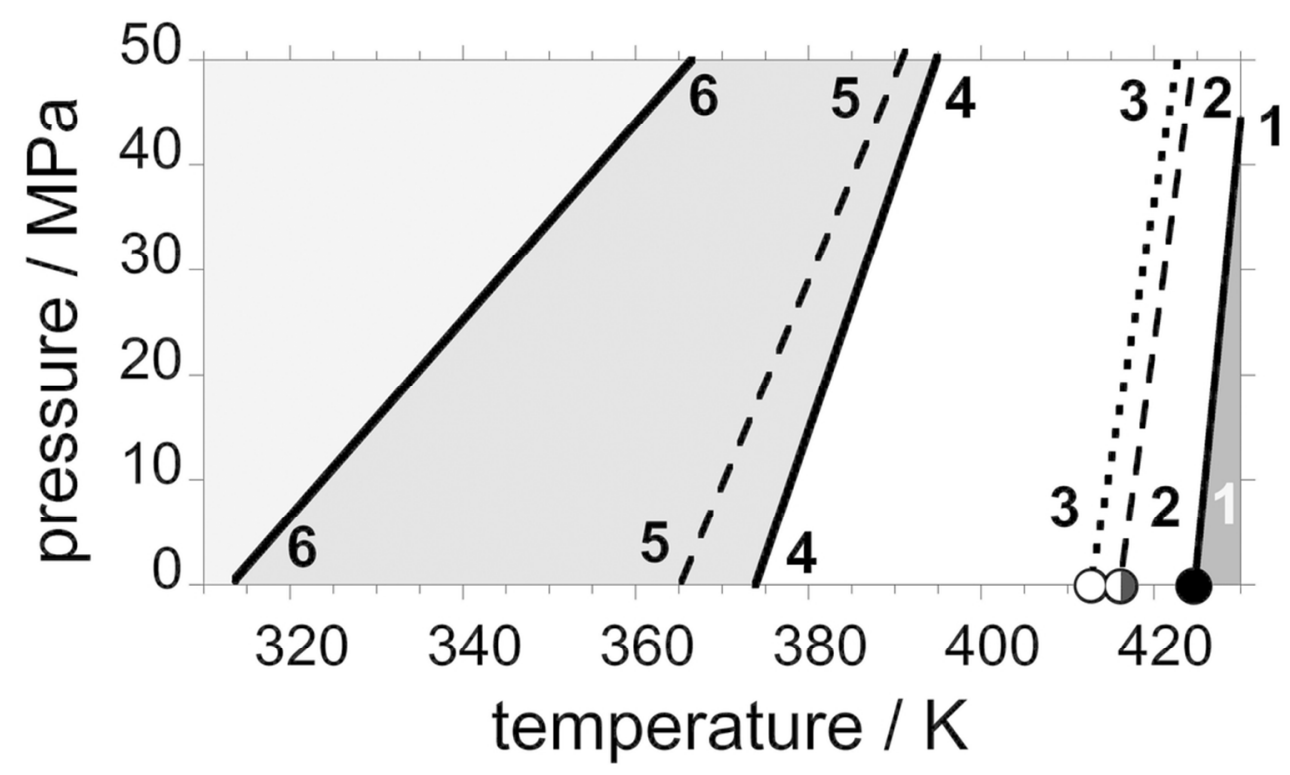

Figure 5b. Detail of the P-T diagram with the three triple points along the liq-vap curve ( $=x$-axis): solid circle: I-liq-vap, stable, half-filled circle: II-liq-vap, metastable, open circle: III-liq-vap, super-metastable. The diagram shows the same two-phase equilibrium lines as in Figure 5a. Stable phase regions: see Figure 5 a.

$48 \times 28 \mathrm{~mm}(600 \times 600 \mathrm{DPI})$ 


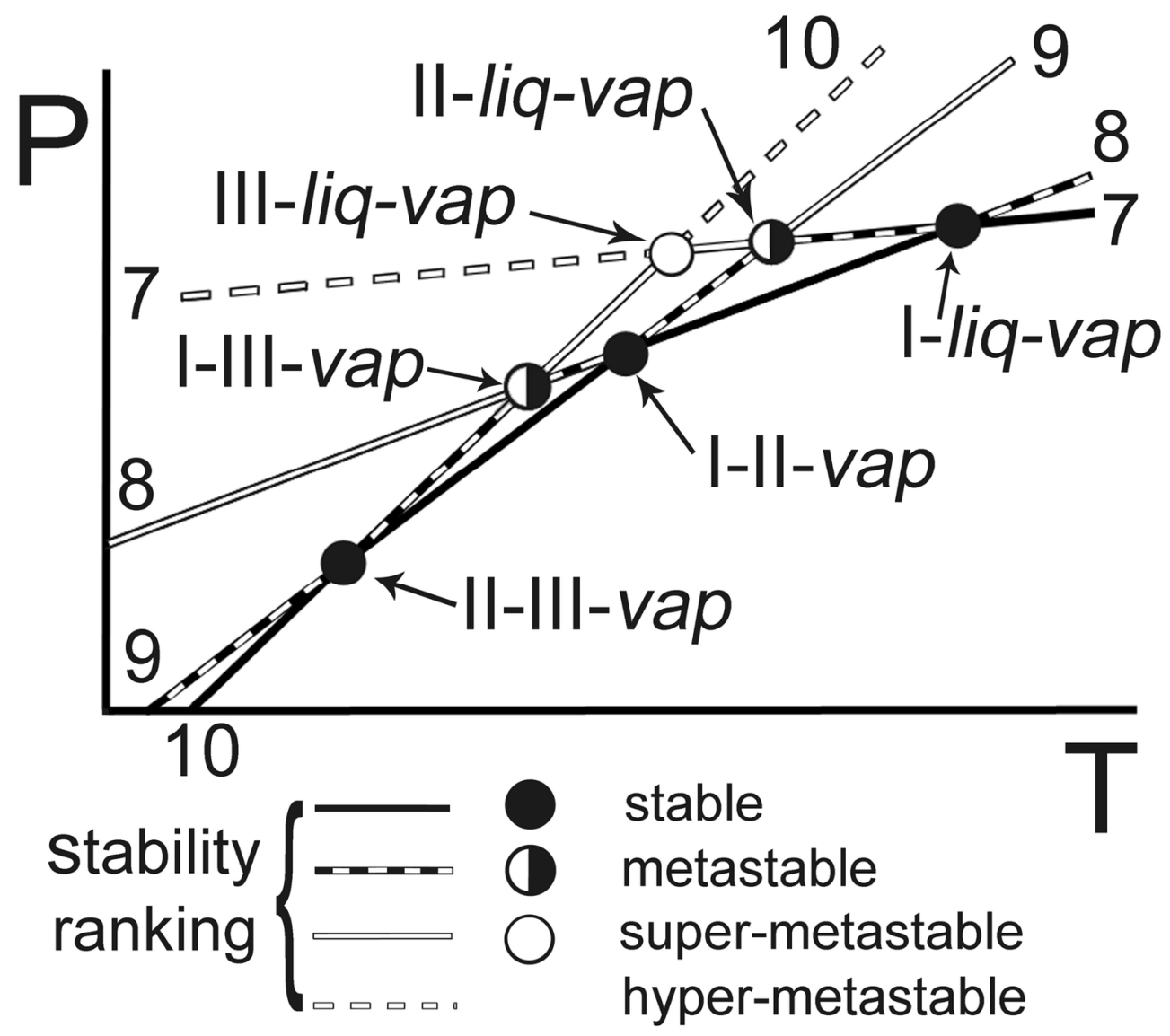

Figure 6. Topological representation of the two-phase equilibria involving the vapor phase in the $\mathrm{P}-\mathrm{T}$ diagram of piracetam: 7 = liquid-vapor equilibrium, $8=$ I-vapor, $9=$ II-vapor, $10=$ III-vapor $70 \times 62 \mathrm{~mm}(600 \times 600 \mathrm{DPI})$ 


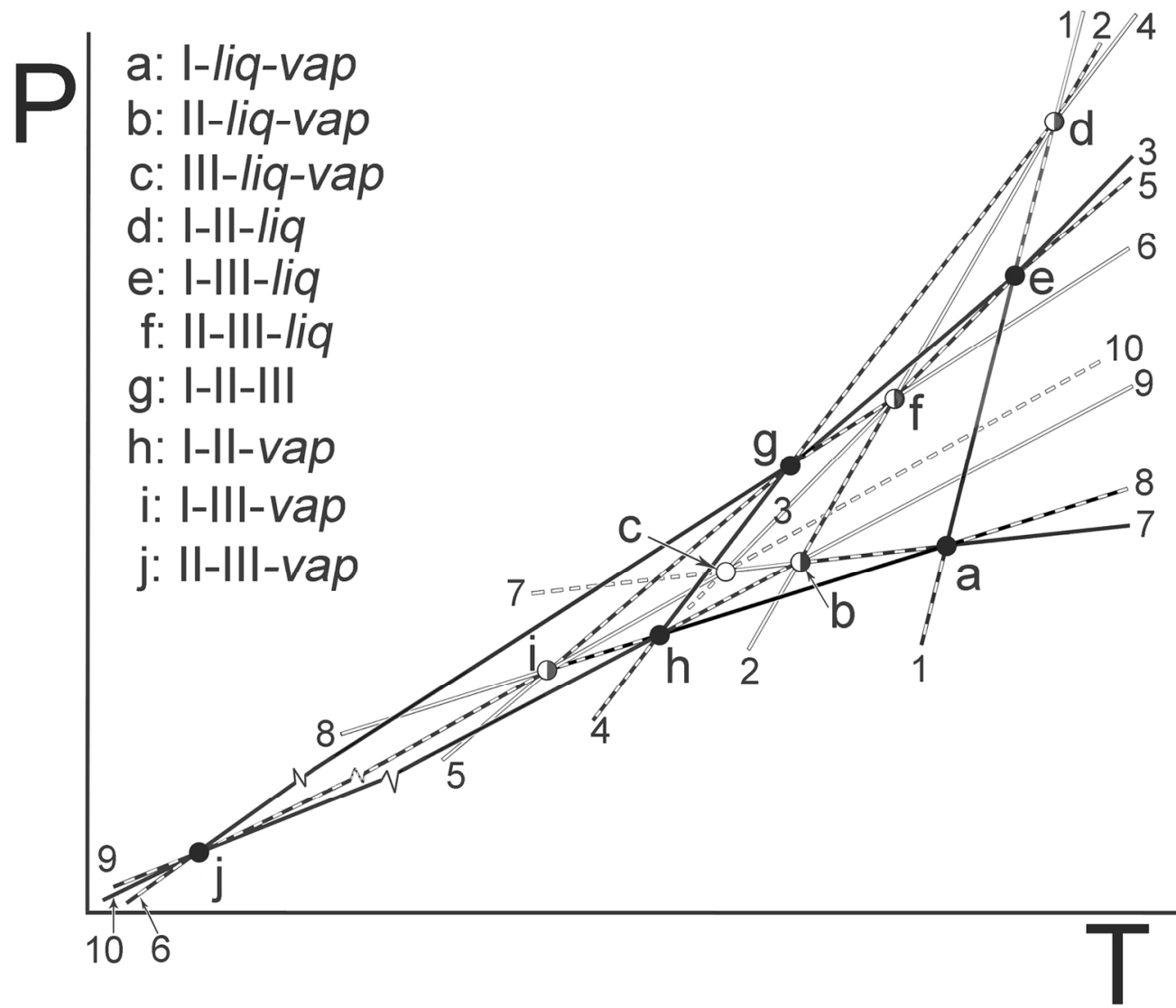

Figure 7a. Complete topological P - T diagram for the phase relationships involving forms I, II and III of piracetam. Two-phase equilibrium curves: same numbering as in Figures 5 and 6 . Stability ranking: same as in figure 6 .

$68 \times 59 \mathrm{~mm}(600 \times 600$ DPI $)$

John Wiley \& Sons, Inc. 


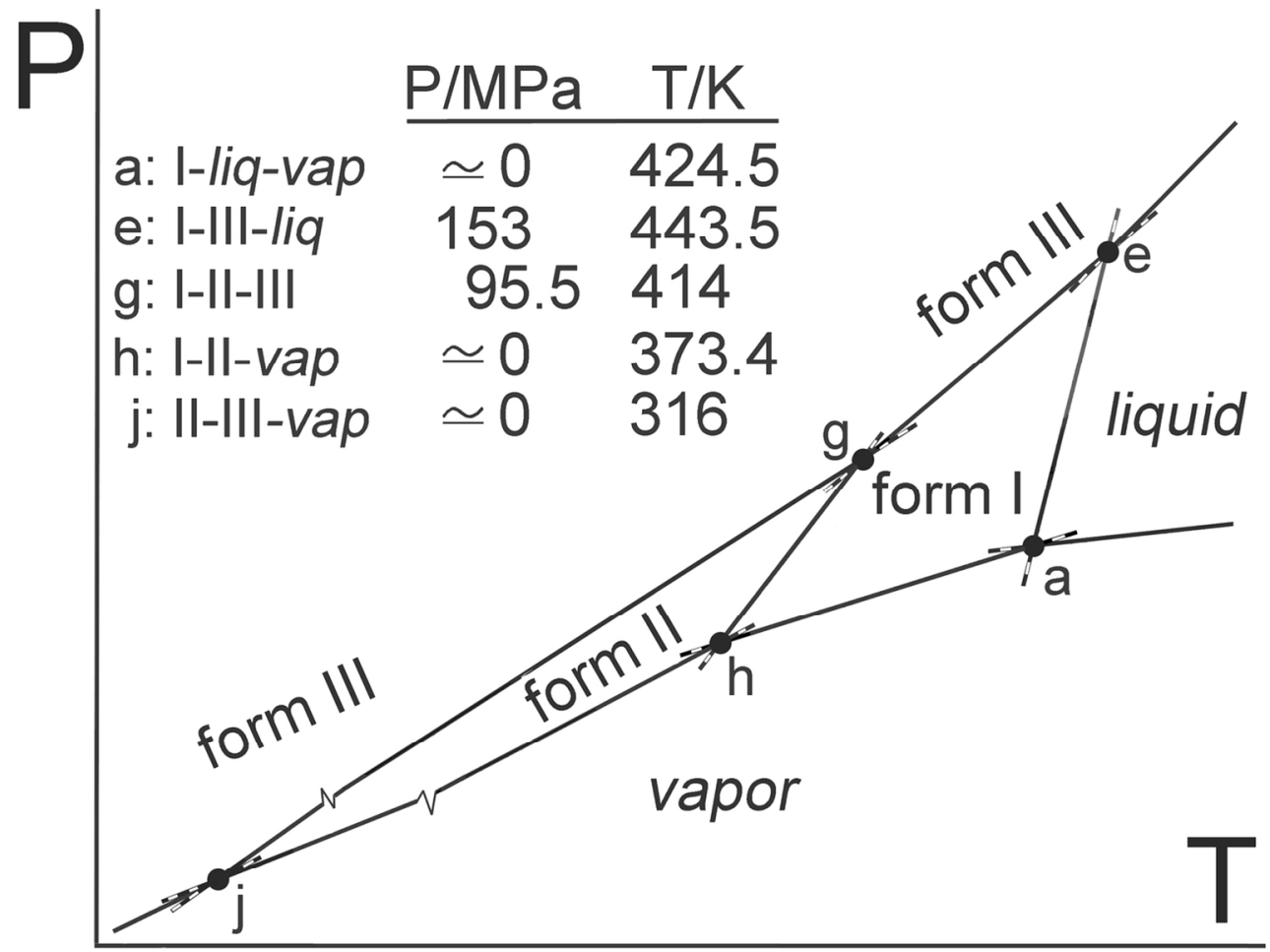

Figure 7b. Topological representation of the stable P-T diagram. The stable phase regions are shown and delimited by the equilibrium curves connecting the five stable triple points (from ten in total). Form III is stable under ambient conditions. $63 \times 49 \mathrm{~mm}(600 \times 600 \mathrm{DPI})$ 


\section{Tables}

Table 1. Specific volumes ( $v$ ) from the literature of the three solid forms of piracetam obtained under ambient conditions

\begin{tabular}{|l|l|l|l|l|}
\hline Form & System, space group & $\begin{array}{l}v \\
/ \mathrm{cm}^{3} \mathrm{~g}^{-1}\end{array}$ & $\begin{array}{l}T \\
/ \mathrm{K}\end{array}$ & Ref. \\
\hline I & Monoclinic P2 $1 / \mathrm{n}$ & 0.7661 & R.T. & 9 \\
& & 0.7518 & 150 & 7 \\
\hline II & Triclinic P-1 & 0.7383 & R.T. & 10 \\
& & 0.7094 & 100 & 11 \\
\hline III & Monoclinic P2 $1 / \mathrm{n}$ & 0.7216 & R.T. & 12 \\
& & 0.7321 & R.T. & 10 \\
& & 0.7245 & R.T. & 13 \\
& & 0.7251 & 290 & 14 \\
& & 0.7058 & 100 & 11 \\
\hline
\end{tabular}

Table 2. Calorimetric data for piracetam forms I, II, and III from the literature

\begin{tabular}{|l|l|l|l|l|l|l|l|l|}
\hline $\begin{array}{l}T_{\mathrm{II}-\mathrm{I}} \\
/ \mathrm{K}\end{array}$ & $\begin{array}{l}\Delta_{\text {II } \rightarrow \text { I }} h \\
/ \mathrm{J} \mathrm{g}^{-1}\end{array}$ & $\begin{array}{l}T_{\mathrm{III-I}} \\
/ \mathrm{K}\end{array}$ & $\begin{array}{l}\Delta_{\text {III } \rightarrow \text { I }} h \\
/ \mathrm{J} \mathrm{g}^{-1}\end{array}$ & $\begin{array}{l}T_{\text {I-liq }} \\
/ \mathrm{K}\end{array}$ & $\begin{array}{l}\Delta_{\mathrm{I} \rightarrow \text { liq }} h \\
/ \mathrm{J} \mathrm{g}^{-1}\end{array}$ & $\begin{array}{l}T_{\text {III-liq }} \\
/ \mathrm{K}\end{array}$ & $\begin{array}{l}\Delta_{\text {III } \rightarrow \text { liq }} h \\
/ \mathrm{J} \mathrm{g}^{-1}\end{array}$ & Ref. \\
\hline 382 & 23.71 & 393 & 26.45 & - & - & - & - & 14 \\
382 & 23.92 & 392 & 26.73 & 423 & 179.38 & - & - & 5 \\
\hline 348 or 377 & 21 & 390 & 26.7 & 426 & 180.7 & 413 & 206 & 3 \\
\hline 399 & 24 & 392 & 28 & 426 & 180 & 412 & 210 & 6 \\
\hline 382.7 & 22.72 & 394.4 & 26.24 & 425.9 & $\begin{array}{l}176.6 \text { or } \\
182.9\end{array}$ & & & 4 \\
\hline
\end{tabular}

John Wiley \& Sons, Inc. 
Table 3. Summary of the calorimetric data obtained for forms I, II, and III of piracetam from 5 series of DSC experiments (see Tables S2 to S5 in the Supporting Information)

\begin{tabular}{|l|l|l|l|l|l|}
\hline & $\begin{array}{l}\text { Number } \\
\text { of values }\end{array}$ & $\begin{array}{l}\text { Lowest } \\
\text { value }\end{array}$ & $\begin{array}{l}\text { Highest } \\
\text { value }\end{array}$ & Mean & $\begin{array}{l}\text { Standard } \\
\text { deviation }\end{array}$ \\
\hline$T_{\text {II-I }} / \mathrm{K}^{\mathrm{a}}$ & 12 & 372.9 & 402.8 & 390.6 & 9.4 \\
\hline$T_{\text {III-I }} / \mathrm{K}^{\mathrm{a}}$ & 18 & 363.3 & 406.9 & 389.0 & 12.5 \\
\hline$\Delta_{\text {II } \rightarrow \mathrm{I}} h / \mathrm{J} \mathrm{g}^{-1}$ & 23 & 22.9 & 25.9 & 24.4 & 0.9 \\
\hline$\Delta_{\text {III } \rightarrow \text { I }} h / \mathrm{J} \mathrm{g}^{-1}$ & 26 & 25.2 & 30.1 & 27.5 & 1.2 \\
\hline$\Delta_{\mathrm{I} \rightarrow \text { liq }} h / \mathrm{J} \mathrm{g}^{-1}$ & 49 & 174.9 & 195.4 & 187.1 & 4.3 \\
\hline$T_{\mathrm{I}-\text { liq }} / \mathrm{K}$ & 49 & 423.3 & 425.6 & 424.5 & 0.5 \\
\hline$\Delta_{\text {III } \rightarrow \text { liq }} h / \mathrm{J} \mathrm{g}-1$ & 7 & $(205.0)$ & $(217.1)$ & $(211.5)$ & 4.4 \\
& & $207.1^{\mathrm{b}}$ & $219.3^{\mathrm{b}}$ & $213.6^{\mathrm{a}}$ & \\
\hline$T_{\text {III-liq }} / \mathrm{K}$ & 7 & 411.9 & 412.8 & 412.3 & 0.34 \\
\hline
\end{tabular}

aAverage for 5 and $10 \mathrm{~K} \mathrm{~min}^{-1}$ only

bValues adjusted for the presence of 1 mass $\%$ of methanol in form III, the measured apparent melting enthalpies are provided in parentheses.

Table 4. Triple point coordinates I-II-liq, I-III-liq and II-III-liq determined directly from high-pressure data and by the Clapeyron equation (topological approach)

\begin{tabular}{|l|l|l|l|l|l|l|}
\hline & \multicolumn{3}{|l|}{ I-II-liq } & \multicolumn{2}{l|}{ I-III-liq } & \multicolumn{2}{l|}{ II-III-liq } \\
\hline & $P / \mathrm{MPa}$ & $T / \mathrm{K}$ & $P / \mathrm{MPa}$ & $T / \mathrm{K}$ & $P / \mathrm{MPa}$ & $T / \mathrm{K}$ \\
\hline High-pressure data & 182 & 450 & 153 & 443 & 117 & 436 \\
\hline $\begin{array}{l}\text { Topological data with } \\
\text { TII-liq = 413 K }\end{array}$ & 501 & 529 & 250 & 477 & 27 & 419 \\
\hline $\begin{array}{l}\text { Topological data with } \\
\text { TII-liq = 415 K }\end{array}$ & 361 & 500 & 250 & 477 & 120 & 443 \\
\hline
\end{tabular}




\title{
Supporting Information for the paper:
}

\author{
Stability Hierarchy between Piracetam \\ Forms I, II and III from Experimental
}

Pressure-Temperature Diagrams and

Topological Inferences

Authors: Siro Toscani, René Céolin, Léon Ter Minassian, Maria Barrio, Nestor Veglio, Josep-Lluis Tamarit, Daniel Louër, Ivo B. Rietveld 
Table S1. Crystallographic data for piracetam polymorphs

\begin{tabular}{|c|c|c|c|c|c|c|c|c|c|}
\hline & Form I & Form I & Form II & Form III & Form III & Form III & Form III & Form II & Form III \\
\hline $\begin{array}{l}\text { Space } \\
\text { group }\end{array}$ & $\mathrm{P} 2_{1} / \mathrm{n}$ & $\mathrm{P} 2_{1} / \mathrm{n}$ & $\mathrm{P}-1$ & $\mathrm{P} 21 / \mathrm{n}$ & $\mathrm{P} 2_{1} / \mathrm{n}$ & $\mathrm{P} 2{ }_{1} / \mathrm{n}$ & $\mathrm{P} 2{ }_{1} / \mathrm{n}$ & P-1 & $\mathrm{P} 2_{1} / \mathrm{n}$ \\
\hline$a / \AA$ & 6.747 & 6.7254 & 6.403 & 16.376 & 6.525 & 16.403 & 6.503 & 6.3530 & 6.4539 \\
\hline$b / \AA$ & 13.418 & 13.2572 & 6.618 & 6.413 & 6.440 & 6.417 & 6.418 & 6.5278 & 6.3857 \\
\hline$c / \AA$ & 8.090 & 8.0529 & 8.556 & 6.493 & 16.463 & 6.504 & 16.416 & 8.3716 & 16.1814 \\
\hline$\alpha /^{\circ}$ & & & 79.85 & & & & & 80.297 & \\
\hline$\beta /{ }^{\circ}$ & 99.01 & 98.603 & 102.39 & 92.21 & 92.19 & 92.05 & 92.087 & 78.226 & 92.05 \\
\hline$\gamma /{ }^{\circ}$ & & & 91.09 & 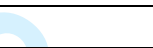 & & & & 89.048 & \\
\hline$V$ cell $/ \AA^{3}$ & 723.36 & 709.92 & 348.58 & 681.38 & 691.29 & 684.160 & 684.69 & 334.96 & 666.45 \\
\hline$Z$ & 4 & 4 & 2 & 4 & 4 & 4 & 4 & 2 & 4 \\
\hline$T / \mathrm{K}$ & R.T. & 150 & R.T. & R.T. & R.T. & R.T. & 290 & 100 & 100 \\
\hline $\mathrm{v} / \mathrm{cm}^{3} \mathrm{~g}^{-1}$ & 0.766052 & 0.751816 & 0.738310 & 0.721597 & 0.732085 & 0.724538 & 0.725097 & 0.709449 & 0.705785 \\
\hline $\begin{array}{l}\text { Melting } \\
\text { point }\end{array}$ & & & & $154^{\circ} \mathrm{C}$ & & $138^{\circ} \mathrm{C}$ & & & \\
\hline $\begin{array}{l}\text { Ref. } \\
\text { (paper) }\end{array}$ & 9 & 7 & 10 & 12 & 10 & 13 & 14 & 11 & 11 \\
\hline
\end{tabular}

Table S2. First series of DSC experiments, performed in 1993 with a TA Instruments DSC10 Thermal Analyzer

\begin{tabular}{|l|l|l|l|l|l|l|l|}
\hline $\begin{array}{l}\text { Origin/ } \\
\text { comment }\end{array}$ & $\begin{array}{l}\text { Heating } \\
\text { rate/ } \\
\text { K min-1 }\end{array}$ & $\begin{array}{l}\text { Mass/ } \\
\mathrm{mg}\end{array}$ & $\begin{array}{l}\mathrm{T}_{\text {trans }} / \mathrm{K} \\
\text { (onset) }\end{array}$ & $\begin{array}{l}\Delta_{\text {trans }} \mathrm{H} / \\
\mathrm{J} \mathrm{g}^{-1}\end{array}$ & $\begin{array}{l}\mathrm{T}_{\text {fus }} / \\
\mathrm{K} \\
\text { (onset) }\end{array}$ & $\begin{array}{l}\Delta_{\text {fus }} \mathrm{H} / \\
\mathrm{J} \mathrm{g}^{-1}\end{array}$ & $\begin{array}{l}\text { Identification } \\
\text { of the initial } \\
\text { form }\end{array}$ \\
\hline $\begin{array}{l}\text { As received. no } \\
\text { recrystallization }\end{array}$ & 10 & 23.95 & 394.41 & 25.49 & 424.22 & 185.0 & Form III \\
\hline $\begin{array}{l}\text { As received. no } \\
\text { recrystallization }\end{array}$ & 10 & 23.95 & 393.33 & 25.50 & 424.22 & 176.9 & Form III \\
\hline $\begin{array}{l}\text { Recrystallized } \\
\text { from isobutanol }\end{array}$ & 10 & 14.60 & 394.32 & 23.71 & 423.94 & 182.6 & Form II \\
\hline $\begin{array}{l}\text { Recrystallized } \\
\text { from isobutanol }\end{array}$ & 10 & 14.60 & 395.33 & 24.96 & 424.94 & 189.3 & Form II \\
\hline $\begin{array}{l}\text { Recrystallized } \\
\text { from isobutanol }\end{array}$ & 10 & 14.60 & 395.31 & 23.97 & 424.94 & 181.1 & Form II \\
\hline $\begin{array}{l}\text { Recrystallized } \\
\text { from isobutanol } \\
+5 \% \text { water }\end{array}$ & 10 & 8.62 & 395.55 & 22.89 & 425.07 & 188.8 & Form II \\
\hline
\end{tabular}


Table S3. Second series of DSC experiments, performed in 1996 with a TA Instruments DSC10 Thermal Analyzer

\begin{tabular}{|c|c|c|c|c|c|c|c|}
\hline $\begin{array}{l}\text { Identification } \\
\text { of the initial } \\
\text { form }\end{array}$ & $\begin{array}{l}\text { Obtention } \\
\text { footnotes }\end{array}$ & $\begin{array}{l}\text { Heating rate } \\
/ \mathrm{K} \mathrm{min}^{-1}\end{array}$ & $\begin{array}{l}\text { Mass } \\
/ \mathrm{mg}\end{array}$ & $\begin{array}{l}\mathrm{T}_{\text {trans }} / \mathrm{K} \\
\text { (onset) }\end{array}$ & $\begin{array}{l}\Delta_{\text {trans }} \mathrm{H} \\
/ \mathrm{Jg}^{-1}\end{array}$ & $\begin{array}{l}\mathrm{T}_{\text {fus }} / \mathrm{K} \\
\text { (onset) }\end{array}$ & $\begin{array}{l}\Delta_{\text {fus }} \mathrm{H} \\
/ \mathrm{Jg}^{-1}\end{array}$ \\
\hline Form III & $\mathrm{a} 1$ & 5 & 6.39 & 363.33 & 27.24 & 423.95 & 185.0 \\
\hline Form II & $\mathrm{a} 2$ & 5 & 9.13 & 377.84 & 24.21 & 425.18 & 183.5 \\
\hline Form III & $\mathrm{b}$ & 5 & 14.18 & 364.98 & 27.41 & - & - \\
\hline Form III & $\mathrm{C}$ & +2 & 7.21 & 368.74 & 28.24 & 423.69 & 190.5 \\
\hline Form II & $\mathrm{d}$ & +2 & 5.58 & 372.35 & 23.04 & 425.24 & 186.2 \\
\hline Form II & $\mathrm{e}$ & 5 & 18.07 & 378.97 & 24.67 & 424.39 & 186.2 \\
\hline Form III & $\mathrm{f}$ & 5 & 13.93 & 383.14 & 27.07 & 424.65 & 184.5 \\
\hline Form? & $\mathrm{f} 2$ & 5 & 10.33 & - & - & 425.10 & 187.4 \\
\hline Form III & $\mathrm{g}$ & 5 & - & 383.20 & 27.43 & - & - \\
\hline Form? & g2 & 5 & 19.59 & - & - & 425.57 & 186.7 \\
\hline Form III & $\mathrm{h}$ & 10 & 11.00 & 396.60 & 28.00 & 425.37 & 192.5 \\
\hline Form III & $\mathrm{i}$ & 10 & 11.67 & 406.86 & 26.78 & 425.26 & 189.1 \\
\hline form III & $\mathrm{i}$ & 5 & 11.70 & - & - & 412.65 & 205.0 \\
\hline Form III & $\mathrm{i}$ & 5 & 10.29 & 400.28 & 27.25 & 424.68 & 186.7 \\
\hline Form III & j1 & 5 & 18.37 & 397.58 & 27.23 & 424.72 & 186.0 \\
\hline Form I & $\mathrm{j} 2$ & 5 & 18.37 & - & - & 424.34 & 184.5 \\
\hline Form III & $\mathrm{k}$ & 5 & 12.66 & 390.12 & 27.74 & 424.71 & 188.3 \\
\hline Form II & 1 & 5 & - & 399.00 & 23.56 & - & - \\
\hline Form II & $\mathrm{m}$ & 5 & 10.43 & 393.13 & 23.56 & 425.41 & 185.2 \\
\hline Form II & $\mathrm{n}$ & 5 & 11.40 & 394.88 & 22.93 & 424.53 & 185.5 \\
\hline
\end{tabular}

$\mathbf{a 1}=$ after grinding form II with pestle and mortar. $\mathbf{a} 2$ = crystallized from isobutanol $+5 \%$ water solution then ground with pestle and mortar. $\mathbf{b}=$ form III obtained after a 30 -mn ball milling of form II (itself obtained by recrystallization from a solution in a mixture of isobutanol $+5 \%$ water). $\mathbf{c}=$ obtained after ball milling for 30 min of a form-II specimen containing $1 \%$ of form III. $\mathbf{d}=$ obtained after ball milling of form I (itself obtained by heating form III to $403 \mathrm{~K}$ then quenching to room temperature). $\mathbf{e}=$ from form I recrystallized from the melt then annealed for 3.5 months at room temperature. $\mathbf{f}=$ form III submitted to a uniaxial pressure od $0.2 \mathrm{GPa}$. $\mathbf{f} \mathbf{2}=$ unidentified form obtained by recrystallization from a solution in a mixture of isobutanol $+5 \%$ water then submitted to a uniaxial pressure of $0.2 \mathrm{GPa}$. $\mathbf{g}=$ after being subjected to a uniaxial pressure of $1 \mathrm{GPa}$. $\mathbf{g} 2=$ unidentified form obtained after heating to $407 \mathrm{~K}$ then subjected to a uniaxial pressure of $1 \mathrm{GPa} . \mathbf{h}=$ recrystallized from a solution in isobutanol. $\mathbf{i}=$ recrystallized from a solution in methanol then maintained under a dynamic vacuum for 1.5 month. $\mathbf{j} \mathbf{1}=$ specimen as received from the supplier. $\mathbf{j} \mathbf{2}=$ reheating of specimen $\mathbf{j} 1$ just after being cooled to room temperature. $\mathbf{k}=$ another specimen as received from the supplier. $\mathbf{l}$ and $\mathbf{m}=$ recrystallized from a solution in a mixture of isobutanol $+5 \%$ water. $\mathbf{n}=$ specimen as received from the supplier. 
Table S4. Third series of experiments using a TA Instruments Q100 Thermal Analyzer, 2009, July 8, heating rate $10 \mathrm{~K}$ min-1, initial sample: form III

\begin{tabular}{|l|l|l|l|l|}
\hline Mass $/ \mathrm{mg}$ & $\begin{array}{l}\mathrm{T}_{(\mathrm{III} \rightarrow \mathrm{I}) / \mathrm{K}} \\
\text { onset) }\end{array}$ & $\Delta_{\mathrm{III} \rightarrow \mathrm{I} / \mathrm{Jg}^{-1}}$ & $\begin{array}{l}\mathrm{T}_{\text {fus }} / \mathrm{K} \\
(\text { onset })\end{array}$ & $\Delta_{\text {fus }} \mathrm{H} / \mathrm{Jg}^{-1}$ \\
\hline- & - & - & 423.33 & $187.8^{\mathrm{a}}$ \\
\hline 4.39 & - & - & 411.92 & $212.1^{\mathrm{b}}$ \\
\hline 4.44 & - & - & 412.16 & $214.6^{\mathrm{b}}$ \\
\hline 6.44 & & & 412.75 & $214.9^{\mathrm{b}}$ \\
\hline 5.48 & 391.94 & 28.4 & 424.46 & $190.7^{\mathrm{a}}$ \\
\hline 4.10 & - & - & 412.35 & $207.9^{\mathrm{b}}$ \\
\hline 4.18 & 401.74 & 25.2 & 424.19 & $191.0^{\mathrm{a}}$ \\
\hline 6.17 & 391.03 & 28.6 & 424.38 & $191.7^{\mathrm{a}}$ \\
\hline 3.75 & - & - & 412.63 & $217.1^{\mathrm{b}}$ \\
\hline 3.15 & 397.65 & 28.2 & 424.26 & $192.7^{\mathrm{a}}$ \\
\hline
\end{tabular}

amelting of form I

bmelting of form III

Table S5. Fourth series (4a, 4b, 4c) of experiments using a TA_Instruments Q100 Thermal Analyzer July and August 2009

\begin{tabular}{|l|l|l|l|l|l|l|l|}
\hline Series 4a & $\begin{array}{l}\text { Heating } \\
\text { rate } \\
\mathrm{K} \mathrm{min}^{-1}\end{array}$ & $\begin{array}{l}\text { Mass/ } \\
\mathrm{mg}\end{array}$ & $\begin{array}{l}\mathrm{T}_{\text {trans }} / \mathrm{K} \\
\text { (onset) }\end{array}$ & $\begin{array}{l}\Delta \text { trans } \mathrm{H} / \\
\mathrm{Jg}^{-1}\end{array}$ & $\begin{array}{l}\mathrm{T}_{\text {fus }} / \mathrm{K} \\
\text { (onset) }\end{array}$ & $\begin{array}{l}\Delta \text { fus } \mathrm{H} / \\
\mathrm{J} \mathrm{g}^{-1}\end{array}$ & comments \\
\hline Form II & 2 & 2.64 & 374.81 & 25.37 & 424.20 & 184.76 & \\
\hline Form III & 2 & 4.95 & - & - & 411.95 & 208.89 & $\begin{array}{l}\text { Remains form III up } \\
\text { to melting }\end{array}$ \\
\hline Form III & 2 & 3.14 & 375.92 & 29.36 & 423.99 & 185.86 & $\begin{array}{l}\text { Initial form III that } \\
\text { transforms to form I }\end{array}$ \\
\hline Form IIIc & 10 & 3.05 & 384.44 & 28.61 & 424.43 & 179.96 & $\begin{array}{l}\text { Initial form III that } \\
\text { transforms to form I }\end{array}$ \\
\hline
\end{tabular}

aground with pestle and mortar

bobtained after heating to $358 \mathrm{~K}$

cobtained after heating to $358 \mathrm{~K}$ then grinding with pestle and mortar 
Table S5 cont. Fourth series $4 b^{a}$

\begin{tabular}{|l|l|l|l|l|l|l|}
\hline Series 4b & $\begin{array}{l}\text { Heating rate } \\
\text { K min }^{-1}\end{array}$ & $\begin{array}{l}\text { Mass/ } \\
\mathrm{mg}\end{array}$ & $\begin{array}{l}\mathrm{T}_{\text {trans }} / \mathrm{K} \\
\text { (onset) }\end{array}$ & $\begin{array}{l}\Delta \text { trans } \mathrm{H} / \\
\mathrm{J} \mathrm{g}^{-1}\end{array}$ & $\begin{array}{l}\mathrm{T}_{\text {fus }} / \mathrm{K} \\
\text { (onset) }\end{array}$ & $\begin{array}{l}\Delta_{\text {fus }} \mathrm{H} / \\
\mathrm{J} \mathrm{g}^{-1}\end{array}$ \\
\hline Form II & 10 & 2.40 & 387.93 & 25.74 & 424.39 & 188.32 \\
\hline Form II & 20 & 2.27 & 389.50 & 23.44 & 424.14 & 179.85 \\
\hline Form II & 15 & 1.92 & 390.53 & 23.28 & 424.36 & 174.90 \\
\hline Form II & 5 & 1.76 & 385.03 & 25.17 & 423.87 & 189.20 \\
\hline Form II & 7.5 & 2.20 & 387.95 & 25.93 & 424.75 & 195.14 \\
\hline Form II & 7.5 & 2.40 & 385.35 & 24.65 & 424.18 & 185.46 \\
\hline Form II & 12.5 & 1.87 & 388.44 & 24.43 & 424.31 & 184.14 \\
\hline Form II & 30 & 2.32 & 392.58 & 25.46 & 424.46 & 193.27 \\
\hline Form II & 18 & 2.05 & 385.65 & 25.41 & 424.32 & 189.75 \\
\hline & & & & & & \\
\hline Form III & 20 & 2.05 & 399.76 & 26.63 & 424.24 & 186.67 \\
\hline Form III & 15 & 1.93 & 399.10 & 26.19 & 424.85 & 185.46 \\
\hline Form III & 5 & 2.02 & 380.87 & 30.10 & 423.96 & 195.36 \\
\hline Form III & 7.5 & 3.00 & 382.45 & 28.31 & 423.80 & 187.11 \\
\hline Form III & 12.5 & 2.00 & 392.58 & 28.75 & 424.11 & 189.75 \\
\hline Form III & 30 & 2.53 & 394.94 & 27.58 & 424.21 & 192.61 \\
\hline Form III & 18 & 1.83 & 394.22 & 27.47 & 423.73 & 192.39 \\
\hline
\end{tabular}

aSeries $4 \mathrm{~b}$ has been performed with the same aliquots of forms II and III ground with pestle and mortar.

${ }^{\mathrm{b}} \mathrm{An}$ additional very weak endothermic peak $\left(\Delta \mathrm{H}=0.10-0.7 \mathrm{~J} \mathrm{~g}^{-1}\right)$ is recorded at $410.15-411.53 \mathrm{~K}$ (onset).

The mean values from series $4 \mathrm{a}$ and $4 \mathrm{~b}$ :

Form I: Mean $T_{\text {fus,I }}=424.23 \mathrm{~K}$ (std dev =0.29. std err.=0.07). Mean $\Delta_{\text {fus }} h_{\mathrm{I}}=187.44 \mathrm{~J} / \mathrm{g}$ (std dev.=5.38. std err. $\left.=1.24\right)$

Form III: $T_{\text {fus,III }}=411.95 \mathrm{~K}, \Delta_{\text {fus }} h_{\text {III }}=208.89 \mathrm{~J} / \mathrm{g}$ 
Table S5 cont. Fourth series $4 \mathrm{c}$ - Other measurements with ground forms II and III

\begin{tabular}{|l|l|l|l|}
\hline Form II & $\begin{array}{l}\text { Heating rate/ } \\
\text { K min }^{-1}\end{array}$ & $\begin{array}{l}\text { Mass/ } \\
\mathrm{mg}\end{array}$ & $\begin{array}{l}\text { Ttrans/K } \\
\text { (onset) }\end{array}$ \\
\cline { 2 - 4 } & 25 & 2.68 & 397.59 \\
\cline { 2 - 4 } & 22 & 2.32 & 397.20 \\
\cline { 2 - 4 } & 50 & 2.80 & 395.80 \\
\cline { 2 - 4 } & 1 & 3.10 & 383.43 \\
\hline Form III & 25 & 3.14 & 385.71 \\
\cline { 2 - 4 } & 22 & 2.71 & 386.09 \\
\cline { 2 - 4 } & 1 & 2.75 & 387.84 \\
\cline { 2 - 4 } & 50 & 2.67 & 407.89 \\
\hline
\end{tabular}

Series 5. A fifth series of experiments has been performed with a Mettler-Toledo 822e thermal analyzer.

A specimen of Form III $(2.00 \mathrm{mg})$ showed a transition to form I ( $\mathrm{T}_{\mathrm{III} \rightarrow \mathrm{I}}=393.39 \mathrm{~K}$ (onset), $\left.\Delta_{\mathrm{III} \rightarrow \mathrm{I}} \mathrm{H}=26.80 \mathrm{~J} \mathrm{~g}^{-1}\right)$ on heating at a $10 \mathrm{~K} \mathrm{~min}^{-1}$ rate followed by melting of form I at $\mathrm{T}_{\text {fus, }}=425.13 \mathrm{~K}$ (onset), $\Delta_{\text {fus, }} \mathrm{H}=189.80 \mathrm{~J} \mathrm{~g}^{-1}$.

A specimen of Form II ( $9.77 \mathrm{mg}$ ) heated at the same rate showed first a transition to form $\mathrm{I}$ at $\mathrm{T}_{\mathrm{II} \rightarrow \mathrm{I}}=402.82 \mathrm{~K}$ (onset), $\Delta_{\mathrm{II} \rightarrow \mathrm{I}} \mathrm{H}=23.96 \mathrm{~J} \mathrm{~g}-1$, then a small endothermic peak at $412.46 \mathrm{~K}$ (onset), $\Delta \mathrm{H}=0.40 \mathrm{~J} \mathrm{~g}^{-1}$, followed by melting of form I at $\mathrm{T}_{\text {fus, } \mathrm{I}}=425.07 \mathrm{~K}$ (onset), $\Delta$ fus, $\mathrm{H}=$ $189.31 \mathrm{~J} \mathrm{~g}^{-1}$. On cooling, crystallization started at $360.44 \mathrm{~K}, \Delta_{\text {cryst }} \mathrm{H}=-145 \mathrm{~J} \mathrm{~g}^{-1}$. On reheating at a $10 \mathrm{~K} \mathrm{~min}^{-1} \mathrm{rate}$, only the melting of form I was observed $\left(\mathrm{T}_{\text {fus }, \mathrm{I}}=423.52 \mathrm{~K}\right.$ (onset), $\Delta_{\text {fus, } \mathrm{I}} \mathrm{H}=183.50 \mathrm{~J} \mathrm{~g}^{-1}$ ) thus indicating that the crystallization enthalpy previously observed should be ascribed to form I. 
Table S6a. Unit-cell parameters (with standard deviations in parentheses) and specific volumes for piracetam forms I, II, and III as a function of temperature (measurement series 1). The X-ray powder diffraction data of form I were collected upon cooling, except for three of them (the parameters derived from these three datasets are marked with an asterisk).

\begin{tabular}{|l|l|l|l|l|l|l|l|l|}
\hline \multicolumn{8}{|c|}{ Form II triclinic } \\
\hline $\mathrm{T} / \mathrm{K}$ & $a / \AA$ & $b / \AA$ & $c / \AA$ & $\alpha /{ }^{\circ}$ & $\beta / /^{\circ}$ & $\gamma^{\circ}$ & Vcell(II)/ $/{ }^{3}$ & $\mathrm{v}(\mathrm{II}) / \mathrm{cm}^{3} \mathrm{~g}^{-1}$ \\
\hline 298 & $6.395(2)$ & $6.613(2)$ & $8.531(4)$ & $79.77(4)$ & $102.38(3)$ & $91.14(3)$ & $346.7(2)$ & 0.73432 \\
\hline 313 & $6.406(2)$ & $6.621(3)$ & $8.554(5)$ & $79.79(4)$ & $102.48(7)$ & $91.21(4)$ & $348.6(3)$ & 0.73835 \\
\hline 333 & $6.400(3)$ & $6.629(2)$ & $8.568(5)$ & $79.68(3)$ & $102.56(8)$ & $91.20(5)$ & $349.0(3)$ & 0.73919 \\
\hline 353 & $6.407(2)$ & $6.637(2)$ & $8.593(2)$ & $79.64(2)$ & $102.70(2)$ & $91.18(3)$ & $350.5(2)$ & 0.74237 \\
\hline 373 & $6.401(2)$ & $6.636(3)$ & $8.612(3)$ & $79.55(3)$ & $102.79(3)$ & $91.20(3)$ & $350.7(3)$ & 0.74280 \\
\hline 383 & $6.404(3)$ & $6.654(3)$ & $8.630(3)$ & $79.56(2)$ & $102.94(2)$ & $91.09(2)$ & $352.4(3)$ & 0.74640 \\
\hline
\end{tabular}

\begin{tabular}{|l|l|l|l|l|l|l|}
\hline \multicolumn{7}{|c|}{ Form I monoclinic (from Form II) } \\
\hline $\mathrm{T} / \mathrm{K}$ & $a / \AA$ & $b / \AA$ & $c / \AA$ & $\beta /{ }^{\circ}$ & Vcell $(\mathrm{I}) / \AA^{3}$ & $\mathrm{v}(\mathrm{I}) / \mathrm{cm}^{3} \mathrm{~g}^{-1}$ \\
\hline 298 & $6.759(2)$ & $13.426(4)$ & $8.102(2)$ & $98.95(3)$ & $726.2(4)$ & 0.76906 \\
\hline 313 & $6.763(1)$ & $13.454(2)$ & $8.115(1)$ & $99.06(1)$ & $729.2(2)$ & 0.77224 \\
\hline 323 & $6.769(1)$ & $13.464(2)$ & $8.120(1)$ & $99.12(2)$ & $730.6(2)$ & 0.77372 \\
\hline 333 & $6.772(2)$ & $13.477(3)$ & $8.124(2)$ & $99.10(3)$ & $732.1(3)$ & 0.77531 \\
\hline 353 & $6.776(2)$ & $13.504(3)$ & $8.136(2)$ & $99.21(2)$ & $734.8(3)$ & 0.77817 \\
\hline 373 & $6.779(2)$ & $13.526(2)$ & $8.150(1)$ & $99.31(2)$ & $737.5(3)$ & 0.78103 \\
\hline 383 & $6.780(1)$ & $13.543(2)$ & $8.158(1)$ & $99.35(2)$ & $739.1(2)$ & 0.78272 \\
\hline 393 & $6.787(2)^{*}$ & $13.563(2)^{*}$ & $8.172(2)^{*}$ & $99.38(2)^{*}$ & $742.2(3)^{*}$ & $0.78600^{*}$ \\
\hline 398 & $6.793(2)$ & $13.564(3)$ & $8.170(2)$ & $99.41(3)$ & $742.6(3)$ & 0.78643 \\
\hline 403 & $6.791(1)^{*}$ & $13.577(2)^{*}$ & $8.180(1)^{*}$ & $99.43(2)^{*}$ & $744.0(2)^{*}$ & $0.78791^{*}$ \\
\hline 413 & $6.797(2)^{*}$ & $13.588(2)^{*}$ & $8.190(2)^{*}$ & $99.48(2)^{*}$ & $746.1(3)^{*}$ & $0.79013^{*}$ \\
\hline
\end{tabular}




\begin{tabular}{|l|l|l|l|l|l|l|}
\hline \multicolumn{7}{|c|}{ Form III monoclinic } \\
\hline $\mathrm{T} / \mathrm{K}$ & $a / \AA$ & $b / \AA$ & $c / \AA$ & $\beta /{ }^{\circ}$ & Vcell $(\mathrm{III}) / \AA^{3}$ & $\mathrm{v}(\mathrm{III}) / \mathrm{cm}^{3} \mathrm{~g}^{-1}$ \\
\hline 298 & $6.513(3)$ & $6.426(2)$ & $16.419(3)$ & $92.09(2)$ & $686.7(3)$ & 0.72723 \\
\hline 313 & $6.517(3)$ & $6.435(3)$ & $16.434(4)$ & $92.13(2)$ & $688.9(4)$ & 0.72956 \\
\hline 333 & $6.529(2)$ & $6.443(2)$ & $16.475(2)$ & $92.15(2)$ & $692.6(3)$ & 0.73348 \\
\hline 353 & $6.526(2)$ & $6.449(2)$ & $16.505(3)$ & $92.17(2)$ & $694.2(3)$ & 0.73517 \\
\hline 373 & $6.533(2)$ & $6.460(2)$ & $16.518(5)$ & $92.22(2)$ & $696.6(3)$ & 0.73771 \\
\hline
\end{tabular}

\begin{tabular}{|l|l|l|l|l|l|l|}
\hline \multicolumn{7}{|c|}{ Form I monoclinic (from Form III) } \\
\hline $\mathrm{T} / \mathrm{K}$ & $a / \AA$ & $b / \AA$ & $c / \AA$ & $\beta /{ }^{\circ}$ & Vcell $(\mathrm{I}) / \AA^{3}$ & $\mathrm{v}(\mathrm{I}) / \mathrm{cm}^{3} \mathrm{~g}^{-1}$ \\
\hline 353 & $6.781(3)$ & $13.502(3)$ & $8.147(2)$ & $99.12(4)$ & $736.5(3)$ & 0.77997 \\
\hline 383 & $6.784(2)$ & $13.539(3)$ & $8.166(2)$ & $99.29(3)$ & $740.2(3)$ & 0.78389 \\
\hline 393 & $6.789(2)$ & $13.562(2)$ & $8.173(1)$ & $99.39(2)$ & $742.4(3)$ & 0.78622 \\
\hline
\end{tabular}


Table S6b. Lattice parameters and specific volumes of forms I, II and III as a function of temperature (measurement series 2)

\begin{tabular}{|c|c|c|c|c|c|c|c|}
\hline \multicolumn{8}{|c|}{ Form II } \\
\hline $\mathrm{T} / \mathrm{K}$ & $\mathrm{a} / \AA ̊$ & $\mathrm{~b} / \AA$ & $\mathrm{c} / \AA$ & $\alpha /^{\circ}$ & $\beta /{ }^{\circ}$ & $\gamma /{ }^{\circ}$ & $\mathrm{v} / \mathrm{cm}^{3} \mathrm{~g}^{-1}$ \\
\hline 100 & 6.358 & 6.535 & 8.376 & 80.26 & 101.79 & 90.93 & 0.71104 \\
\hline 130 & 6.362 & 6.546 & 8.393 & 80.21 & 101.85 & 90.96 & 0.71387 \\
\hline 160 & 6.368 & 6.556 & 8.415 & 80.16 & 101.93 & 90.98 & 0.71719 \\
\hline 190 & 6.373 & 6.566 & 8.439 & 80.10 & 101.99 & 91.01 & 0.72061 \\
\hline 220 & 6.380 & 6.577 & 8.467 & 80.02 & 102.10 & 91.03 & 0.72452 \\
\hline 250 & 6.385 & 6.590 & 8.496 & 79.95 & 102.21 & 91.03 & 0.72855 \\
\hline 280 & 6.392 & 6.601 & 8.525 & 79.89 & 102.28 & 91.06 & 0.73273 \\
\hline 310 & 6.399 & 6.616 & 8.558 & 79.79 & 102.46 & 91.08 & 0.73729 \\
\hline 340 & 6.405 & 6.629 & 8.591 & 79.72 & 102.60 & 91.10 & 0.74172 \\
\hline 355 & 6.407 & 6.636 & 8.606 & 79.67 & 102.69 & 91.13 & 0.74365 \\
\hline 370 & 6.412 & 6.646 & 8.624 & 79.63 & 102.76 & 91.14 & 0.74660 \\
\hline 380 & 6.412 & 6.650 & 8.635 & 79.59 & 102.83 & 91.16 & 0.74770 \\
\hline \multicolumn{8}{|c|}{ Form I from Form II } \\
\hline 400 & 6.789 & 13.556 & 8.174 & 90 & 99.35 & 90 & 0.78608 \\
\hline 410 & 6.792 & 13.567 & 8.181 & 90 & 99.37 & 90 & 0.78769 \\
\hline 420 & 6.796 & 13.580 & 8.188 & 90 & 99.40 & 90 & 0.78952 \\
\hline \multicolumn{8}{|c|}{ Form III } \\
\hline 100 & 6.457 & 6.387 & 16.186 & 90 & 92.05 & 90 & 0.70647 \\
\hline 130 & 6.466 & 6.391 & 16.217 & 90 & 92.05 & 90 & 0.70925 \\
\hline 160 & 6.474 & 6.394 & 16.249 & 90 & 92.04 & 90 & 0.71187 \\
\hline 190 & 6.483 & 6.400 & 16.285 & 90 & 92.05 & 90 & 0.71510 \\
\hline 220 & 6.490 & 6.406 & 16.324 & 90 & 92.06 & 90 & 0.71826 \\
\hline 250 & 6.498 & 6.412 & 16.364 & 90 & 92.08 & 90 & 0.72157 \\
\hline 280 & 6.505 & 6.420 & 16.405 & 90 & 92.11 & 90 & 0.72505 \\
\hline 290 & 6.505 & 6.422 & 16.412 & 90 & 92.11 & 90 & 0.72558 \\
\hline 310 & 6.512 & 6.430 & 16.447 & 90 & 92.14 & 90 & 0.72881 \\
\hline 340 & 6.518 & 6.441 & 16.492 & 90 & 92.19 & 90 & 0.73270 \\
\hline 370 & 6.526 & 6.452 & 16.540 & 90 & 92.23 & 90 & 0.73697 \\
\hline 380 & 6.526 & 6.457 & 16.552 & 90 & 92.26 & 90 & 0.73806 \\
\hline \multicolumn{8}{|c|}{ Form I from Form III } \\
\hline 390 & 6.789 & 13.556 & 8.136 & 90 & 99.63 & 90 & 0.78179 \\
\hline 400 & 6.789 & 13.562 & 8.158 & 90 & 99.61 & 90 & 0.78429 \\
\hline 410 & 6.791 & 13.571 & 8.172 & 90 & 99.62 & 90 & 0.78637 \\
\hline 420 & 6.792 & 13.583 & 8.176 & 90 & 99.664 & 90 & 0.78747 \\
\hline
\end{tabular}


Table S7. Specific volume of molten piracetam as a function of temperaturea

\begin{tabular}{|c|c|c|c|c|c|}
\hline $\mathrm{T} / \mathrm{K}$ & $\begin{array}{l}\text { Top of the } \\
\text { melt } \\
/ \mathrm{cm}\end{array}$ & $\begin{array}{l}\text { Bottom of } \\
\text { the melt } \\
/ \mathrm{cm}\end{array}$ & $\begin{array}{l}\text { Height of } \\
\text { the melt } \\
/ \mathrm{cm}\end{array}$ & $\begin{array}{c}\text { Volume of } \\
\text { the melt } \\
/ \mathrm{cm}^{3}\end{array}$ & $\begin{array}{c}\text { Specific volume } \\
\text { of the melt } \\
/ \mathrm{cm}^{3} \mathrm{~g}^{-1}\end{array}$ \\
\hline 427.44 & 42.684 & 25.554 & 17.130 & 8.9408 & 0.88328 \\
\hline 427.44 & 42.684 & 25.530 & 17.154 & 8.9533 & 0.88451 \\
\hline 420.64 & 42.560 & 25.530 & 17.030 & 8.8886 & 0.87812 \\
\hline 420.64 & 42.550 & 25.496 & 17.054 & 8.9011 & 0.87936 \\
\hline 415.79 & 42.492 & 25.486 & 17.006 & 8.8761 & 0.87688 \\
\hline 410.93 & 42.432 & 25.500 & 16.932 & 8.8374 & 0.87307 \\
\hline 430.35 & 42.666 & 25.502 & 17.164 & 8.9585 & 0.88503 \\
\hline 430.35 & 42.678 & 25.500 & 17.178 & 8.9658 & 0.88575 \\
\hline 430.35 & 42.640 & 25.496 & 17.144 & 8.9481 & 0.88400 \\
\hline 435.21 & 42.710 & 25.486 & 17.224 & 8.9898 & 0.88812 \\
\hline 440.06 & 42.814 & 25.518 & 17.296 & 9.0274 & 0.89184 \\
\hline 444.92 & 42.848 & 25.486 & 17.362 & 9.0619 & 0.89524 \\
\hline 432.30 & 42.678 & 25.480 & 17.198 & 8.9763 & 0.88678 \\
\hline 422.58 & 42.539 & 25.480 & 17.059 & 8.9037 & 0.87962 \\
\hline 417.73 & 42.504 & 25.472 & 17.032 & 8.8896 & 0.87822 \\
\hline 415.79 & 42.482 & 25.472 & 17.010 & 8.8781 & 0.87709 \\
\hline 410.93 & 42.426 & 25.474 & 16.952 & 8.8479 & 0.87410 \\
\hline 408.02 & 42.378 & 25.474 & 16.904 & 8.8228 & 0.87162 \\
\hline 404.13 & 42.331 & 25.468 & 16.863 & 8.8014 & 0.86951 \\
\hline 401.22 & 42.293 & 25.468 & 16.825 & 8.7816 & 0.86755 \\
\hline 427.44 & 42.658 & 25.516 & 17.142 & 8.9470 & 0.88389 \\
\hline 418.70 & 42.538 & 25.512 & 17.026 & 8.8865 & 0.87791 \\
\hline 430.35 & 42.643 & 25.498 & 17.145 & 8.9486 & 0.88405 \\
\hline 440.06 & 42.787 & 25.498 & 17.289 & 9.0238 & 0.89147 \\
\hline 444.92 & 42.827 & 25.502 & 17.325 & 9.0426 & 0.89333 \\
\hline 449.78 & 42.884 & 25.502 & 17.382 & 9.0723 & 0.89627 \\
\hline 454.63 & 42.942 & 25.509 & 17.433 & 9.0989 & 0.89890 \\
\hline 454.63 & 42.987 & 25.512 & 17.475 & 9.1209 & 0.90107 \\
\hline 459.49 & 43.008 & 25.530 & 17.478 & 9.1224 & 0.90122 \\
\hline 469.20 & 43.180 & 25.536 & 17.644 & 9.2091 & 0.90978 \\
\hline 410.93 & 42.432 & 25.494 & 16.938 & 8.8406 & 0.87338 \\
\hline 408.99 & 42.390 & 25.500 & 16.890 & 8.8155 & 0.87090 \\
\hline 407.05 & 42.414 & 25.500 & 16.914 & 8.8280 & 0.87214 \\
\hline 405.10 & 42.404 & 25.500 & 16.904 & 8.8228 & 0.87162 \\
\hline 401.22 & 42.350 & 25.498 & 16.852 & 8.7957 & 0.86894 \\
\hline 396.36 & 42.302 & 25.516 & 16.786 & 8.7612 & 0.86554 \\
\hline 396.36 & 42.296 & 25.510 & 16.786 & 8.7612 & 0.86554 \\
\hline
\end{tabular}

anner diameter of the cylindrical silica tube containing the melt measured at various heights from the bottom of the tube: 8.161, 8.157, 8.154, 8.149, $8.140,8.151 \mathrm{~mm}$, Mean diameter: $8.152 \mathrm{~mm}(\mathrm{SD}=0.0073, \mathrm{SEM}=0.0030)$, Mass of piracetam: $10.1223 \mathrm{~g}$ 
Table S8. Piezothermal analysis: experimental melting pressure of forms I and III as a function of temperature, the experimental enthalpy changes, and the specific volume changes ${ }^{\mathrm{a}}$ on melting

\begin{tabular}{|c|c|c|c|c|}
\hline \multicolumn{5}{|c|}{ Melting of form I } \\
\hline$T / \mathrm{K}$ & $P / \mathrm{MPa}$ & $\Delta h / \mathrm{J} \mathrm{g}^{-1}$ & $\Delta s / \mathrm{J} \mathrm{g}^{-1} \mathrm{~K}^{-1}$ & $\Delta v^{\mathrm{a}} / \mathrm{cm}^{3} \mathrm{~g}^{-1}$ \\
\hline $424.46^{b}$ & 0 & $187.10^{b}$ & $0.44080^{b}$ & 0.072700 \\
\hline 428.1 & 20.0 & 186.41 & 0.43542 & 0.071816 \\
\hline 432.9 & 47.0 & 185.00 & 0.42769 & 0.070484 \\
\hline 435.4 & 64.2 & 187.82 & 0.43191 & 0.071145 \\
\hline 438.1 & 81.5 & 186.41 & 0.42487 & 0.070177 \\
\hline \multicolumn{5}{|c|}{ Melting of form III } \\
\hline $412.34^{b}$ & 0 & $211.50^{b}$ & $0.51293^{b}$ & 0.11262 \\
\hline 412.60 & 1.4200 & - & - & - \\
\hline 417.90 & 31.700 & - & - & - \\
\hline 422.50 & 44.800 & 213.14 & 0.50506 & 0.11089 \\
\hline 425.60 & 59.300 & 208.22 & 0.48959 & 0.10749 \\
\hline 428.60 & 71.600 & 195.55 & 0.45653 & 0.10023 \\
\hline 432.50 & 92.100 & 211.03 & 0.48748 & 0.10703 \\
\hline 435.40 & 103.40 & 208.92 & 0.48044 & 0.10548 \\
\hline 438.40 & 121.80 & 209.62 & 0.47763 & 0.10487 \\
\hline 442.30 & 138.70 & 210.33 & 0.47552 & 0.10440 \\
\hline
\end{tabular}

a Volume changes have been calculated with the Clapeyron equation: $\Delta v=\Delta s /(d P / d T)$ and $\mathrm{d} P / \mathrm{d} T=5.96$ from equation 5 a for the fusion of form I and 4.55 from equation 6 a for the fusion of form III

b Mean values at ordinary pressure

The values for the entropy change of form III in Table S8 lead to the expressions $\left(\mathrm{r}^{2}=\right.$ 0.93):

$\Delta s / \mathrm{J} \mathrm{g}^{-1} \mathrm{~K}^{-1}=1.09-0.00140 * T / \mathrm{K}=0.513-0.000302 * P / \mathrm{MPa}$

The value $\Delta s=0.45653 \mathrm{~J} \mathrm{~g}^{-1} \mathrm{~K}^{-1}$ has been ignored.

The values for the specific volume change of form III in Table S8 lead to the expressions $\left(\mathrm{r}^{2}=0.94\right)$ :

$\Delta v / \mathrm{cm}^{3} \mathrm{~g}^{-1}=0.233-0.000292 * T / \mathrm{K}=0.113-6.26^{*} 10^{-5 *} \mathrm{P} / \mathrm{MPa}$

The value $\Delta v=0.10023 \mathrm{~cm}^{3} \mathrm{~g}^{-1}$ has been ignored. 
Table S9. Piezothermal analysis: experimental pressure for transitions III $\rightarrow$ I and II $\rightarrow$ I as a function of temperature, experimental enthalpy changes, and volume changes $^{\text {a }}$ on transition

\begin{tabular}{|c|c|c|c|c|}
\hline$T / \mathrm{K}$ & $P / \mathrm{MPa}$ & $\Delta h / \mathrm{J} \mathrm{g}^{-1}$ & $\Delta s / \mathrm{J} \mathrm{K}^{-1} \mathrm{~g}^{-1}$ & $\Delta \nu^{\mathrm{a}} / \mathrm{cm}^{3} \mathrm{~g}^{-1}$ \\
\hline \multicolumn{5}{|c|}{ transition $\mathrm{III} \rightarrow \mathrm{I}^{\mathbf{b}}$} \\
\hline 378.00 & 33.800 & 30.248 & 0.080020 & 0.042431 \\
\hline 378.20 & 26.400 & 27.434 & 0.072538 & 0.038463 \\
\hline 381.90 & 42.000 & 31.654 & 0.082887 & 0.043951 \\
\hline 382.00 & 35.400 & 30.248 & 0.079182 & 0.041986 \\
\hline 382.90 & 47.400 & 30.951 & 0.080833 & 0.042862 \\
\hline 388.20 & 51.600 & 30.248 & 0.077918 & 0.041316 \\
\hline 393.00 & 61.700 & 31.654 & 0.080546 & 0.042710 \\
\hline 398.10 & 68.500 & 30.951 & 0.077747 & 0.041225 \\
\hline 402.80 & 82.300 & 32.358 & 0.080332 & 0.042596 \\
\hline 402.90 & 70.600 & 30.248 & 0.075075 & 0.039809 \\
\hline 407.90 & 83.300 & 31.654 & 0.077604 & 0.041150 \\
\hline 408.20 & 89.600 & 32.358 & 0.079270 & 0.042033 \\
\hline 410.30 & 89.300 & 31.654 & 0.077150 & 0.040909 \\
\hline 413.10 & 102.00 & 32.358 & 0.078329 & 0.041534 \\
\hline 413.10 & 103.00 & 33.765 & 0.081735 & 0.043340 \\
\hline 415.50 & 99.700 & 30.951 & 0.074491 & 0.039499 \\
\hline 418.00 & 105.20 & 33.061 & 0.079094 & 0.041940 \\
\hline 423.10 & 117.50 & 30.951 & 0.073153 & 0.038789 \\
\hline 432.90 & 136.80 & 33.765 & 0.077997 & 0.041358 \\
\hline 435.40 & 139.80 & 32.358 & 0.074318 & 0.039407 \\
\hline \multicolumn{5}{|c|}{ Transition $\mathbf{I I} \rightarrow \mathbf{I}^{\mathbf{c}}$} \\
\hline$T / \mathrm{K}$ & $\mathrm{P} / \mathrm{MPa}$ & $\Delta H / \mathrm{J} \mathrm{g}^{-1}$ & $\Delta s / \mathrm{J} \mathrm{K}^{-1} \mathrm{~g}^{-1}$ & $\Delta v / \mathrm{cm}^{3} \mathrm{~g}^{-1}$ \\
\hline 375.70 & 7.5000 & & 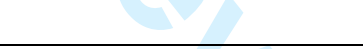 & \\
\hline 383.00 & 23.700 & 26.027 & 0.067956 & 0.028214 \\
\hline 387.90 & 34.800 & 23.917 & 0.061657 & 0.025599 \\
\hline 390.40 & 38.400 & 26.027 & 0.066668 & 0.027679 \\
\hline 393.90 & 47.200 & 26.027 & 0.066075 & 0.027433 \\
\hline 397.90 & 56.900 & 28.137 & 0.070715 & 0.029359 \\
\hline 400.30 & 65.500 & 28.841 & 0.072048 & 0.029913 \\
\hline 405.90 & 81.400 & 28.841 & 0.071054 & 0.029500 \\
\hline
\end{tabular}


Table S10. Melting pressures and temperatures of form I and form III from HPDTA measurements obtained with $2 \mathrm{~K} \mathrm{~min}^{-1}$

\begin{tabular}{|l|l|l|l|l|l|l|l|}
\hline \multicolumn{2}{|l|}{ Melting of form I } & \multicolumn{2}{l|}{ Melting of form III } & \multicolumn{2}{l|}{ Transition III $\rightarrow \mathrm{I}$} & \multicolumn{2}{l|}{ Transition II $\rightarrow \mathrm{I}$} \\
\hline $\mathrm{T} / \mathrm{K}$ & $\mathrm{P} / \mathrm{MPa}$ & $\mathrm{T} / \mathrm{K}$ & $\mathrm{P} / \mathrm{MPa}$ & $\mathrm{T} / \mathrm{K}$ & $\mathrm{P} / \mathrm{MPa}$ & $\mathrm{T} / \mathrm{K}$ & $\mathrm{P} / \mathrm{MPa}$ \\
\hline 425.25 & 0 & 409.60 & 0 & 402.90 & 62.340 & 387.90 & 0 \\
\hline 433.15 & 55.390 & 415.08 & 22.462 & 408.30 & 75.470 & 392.00 & 10.190 \\
\hline 428.75 & 21.180 & 429.70 & 84.150 & 410.00 & 87.980 & 397.00 & 19.900 \\
\hline 429.45 & 31.080 & 435.00 & 112.92 & 415.10 & 101.97 & 396.70 & 30.060 \\
\hline 431.45 & 49.530 & 440.30 & 135.40 & 431.70 & 123.31 & 401.60 & 48.110 \\
\hline 432.35 & 63.420 & 449.60 & 176.27 & 438.70 & 144.68 & 402.90 & 62.340 \\
\hline 434.45 & 76.110 & 453.40 & 211.29 & & & 408.30 & 75.470 \\
\hline 435.75 & 89.010 & 448.75 & 184.31 & & & 410.00 & 87.980 \\
\hline 436.55 & 102.04 & 453.15 & 205.36 & & & 404.40 & 59.260 \\
\hline 426.95 & 16.640 & 453.55 & 214.90 & & & & \\
\hline 431.65 & 60.740 & & & & & & \\
\hline
\end{tabular}

Table S11. Inequalities in the $\mathrm{dP} / \mathrm{dT}$ slopes of the equilibria I-II, I-III and II-III The temperature of triple point I-II-III does not need to be known, but the slopes of the two-phase equilibria can be calculated at a given temperature, for instance at $100 \mathrm{~K}, 300$ $\mathrm{K}$ or $500 \mathrm{~K}$, assuming that the enthalpies and the specific volumes change little with pressure.

Specific volumes as a function of temperature:
$v(\mathrm{I}) / \mathrm{cm}^{3} \mathrm{~g}^{-1}=0.7219+\left(0.00016026^{*} \mathrm{~T} / \mathrm{K}\right)$
equation (1)
$v(\mathrm{II}) / \mathrm{cm}^{3} \mathrm{~g}^{-1}=0.69661+(0.00013037 * \mathrm{~T} / \mathrm{K})$
equation (2)
$v(\mathrm{III}) / \mathrm{cm}^{3} \mathrm{~g}^{-1}=0.69341+(0.00011618 * \mathrm{~T} / \mathrm{K})$
equation (3)

\begin{tabular}{|l|l|l|l|}
\hline$T(\mathrm{~K})$ & $100 \mathrm{~K}$ & $300 \mathrm{~K}$ & $500 \mathrm{~K}$ \\
\hline$V_{\mathrm{I}}$ & 0.73793 & 0.76998 & 0.80203 \\
\hline$V_{\mathrm{II}}$ & 0.70965 & 0.73572 & 0.76179 \\
\hline$V_{\mathrm{III}}$ & 0.70503 & 0.72826 & 0.75150 \\
\hline$V_{\mathrm{I}}-V_{\mathrm{III}}$ & 0.0329 & 0.04172 & 0.05053 \\
\hline$V_{\mathrm{I}}-V_{\mathrm{II}}$ & 0.02828 & 0,03426 & 0.04024 \\
\hline$V_{\mathrm{II}}-V_{\mathrm{III}}$ & 0.00462 & 0.00646 & 0.01029 \\
\hline
\end{tabular}

With $\Delta_{\mathrm{III} \rightarrow \mathrm{I}} h=27.53 \mathrm{~J} / \mathrm{g}$ and $\Delta_{\mathrm{II} \rightarrow \mathrm{I}} h=24.42 \mathrm{~J} / \mathrm{g}, \Delta_{\mathrm{III} \rightarrow \mathrm{II}} h=3.11 \mathrm{~J} / \mathrm{g}$ (from calculation)

Slopes (MPa/K)

\begin{tabular}{|l|l|l|l|}
\hline & $100 \mathrm{~K}$ & $300 \mathrm{~K}$ & $500 \mathrm{~K}$ \\
\hline $\mathrm{dP} / \mathrm{dT}(\mathrm{I}-\mathrm{III})$ & 8.37 & 2.20 & 1.09 \\
\hline $\mathrm{dP} / \mathrm{dT}(\mathrm{I}-\mathrm{II})$ & 8.64 & 2.38 & 1.21 \\
\hline $\mathrm{dP} / \mathrm{dT}$ (II-III) & 6.73 & 1.39 & 0.60 \\
\hline
\end{tabular}

Conclusion: $\mathrm{dP} / \mathrm{dT}_{\mathrm{I}-\mathrm{II}}>\mathrm{dP} / \mathrm{dT}_{\mathrm{I}-\mathrm{III}}>\mathrm{dP} / \mathrm{dT}_{\mathrm{II}-\mathrm{III}}$ 

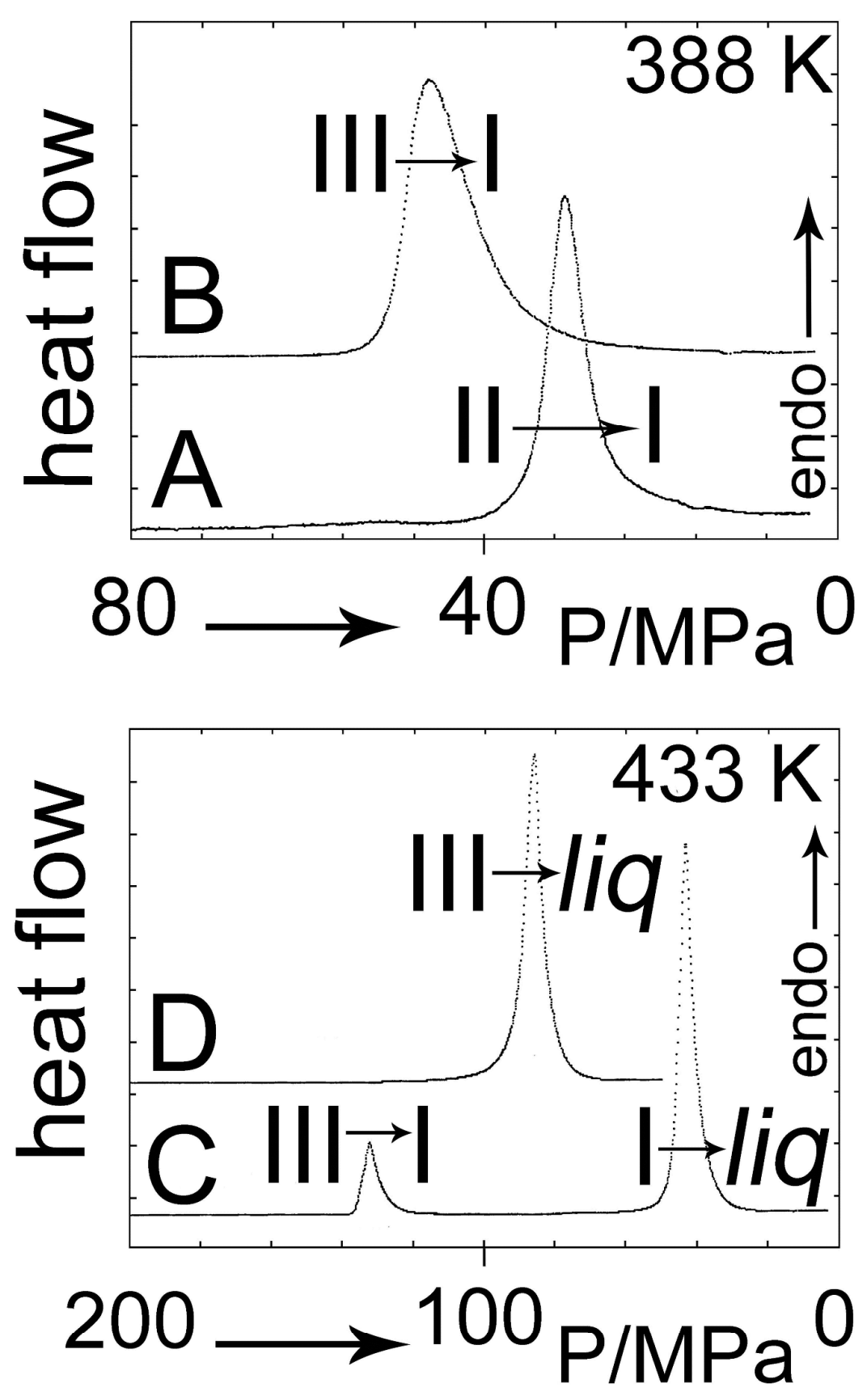

Figure S1. Examples of curves obtained with the piezo-thermal analyzer on decreasing the pressure (arrows along the abscissa). Curves A and B: thermal effects associated to transitions $\mathrm{II} \rightarrow \mathrm{I}$ and $\mathrm{III} \rightarrow \mathrm{I}$ at $388 \mathrm{~K}$, respectively. Curve C: thermal effects recorded using a solvent-free specimen of form III. Curve D: thermal effect recorded using a specimen of form III within which about $1 \%$ of the crystallization solvent was kept, resulting in the melting of form III. 